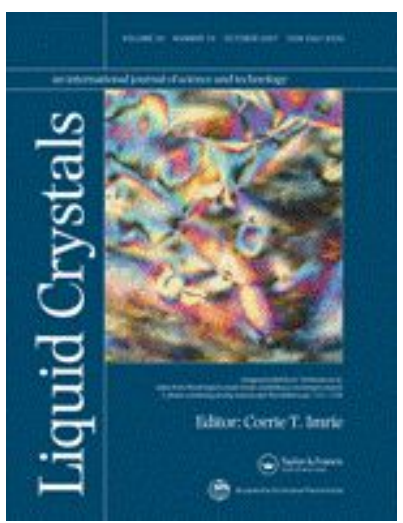

\title{
Glycolipids from Natural Sources: Dry Liquid Crystal Properties, Hydrogen Bonding and Molecular Mobility of Palm Kernel Oil Mannosides
}

\begin{tabular}{|r|l|}
\hline Journal: & Liquid Crystals \\
\hline Manuscript ID & TLCT-2019-0330.R1 \\
\hline Danuscript Type: & Special Issue Article \\
\hline Author: & 20 -Feb-2020 \\
\hline & $\begin{array}{r}\text { Complete List of Authors: } \\
\text { Gelayutham, Thamil Selvi; University of Malaya, Physics } \\
\text { Chemical Engineering; University of Malaya, Chemistry } \\
\text { Engineering } \\
\text { Engarina; Universiti Teknologi MARA, Faculty of Chemical } \\
\text { Farquharson, Emma; University of Aberdeen, School of Engineering } \\
\text { Hashim, Rauzah; University of Malaya, Chemistry }\end{array}$ \\
\hline Keywords: & $\begin{array}{l}\text { Glycolipid, Palm kernel oil, Hydrogen bond, carbohydrate liquid crystals, } \\
\text { FT-IR, Dielectric spectroscopy }\end{array}$ \\
\hline &
\end{tabular}

\section{SCHOLARONE ${ }^{\text {m }}$ Manuscripts}



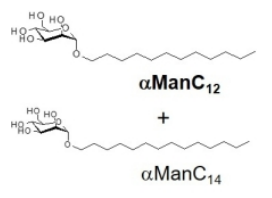

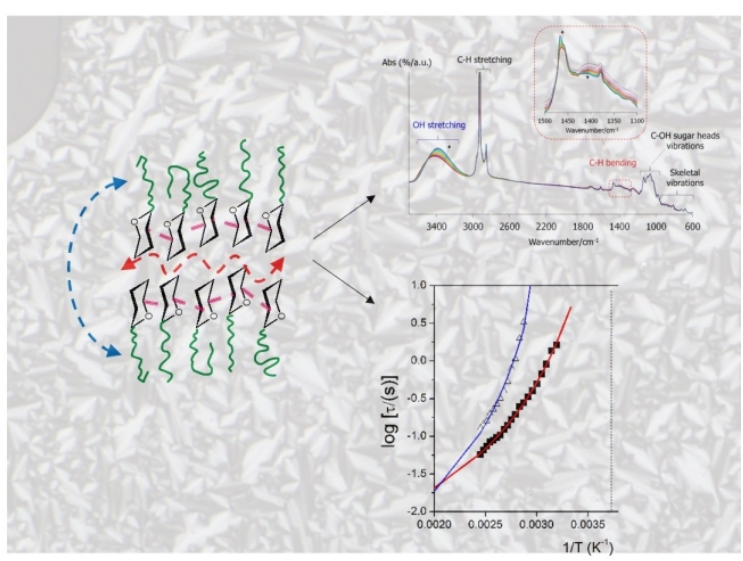

$322 \times 146 \mathrm{~mm}(150 \times 150 \mathrm{DPI})$ 


\section{Glycolipids from Natural Sources: Dry Liquid Crystal Properties, Hydrogen Bonding and Molecular Mobility of Palm Kernel Oil Mannosides}

Alfonso Martinez-Felipe ${ }^{1}$, Thamil Selvi Velayutham²,3, Nurul Fadhilah Kamalul Aripin ${ }^{3,4 *}$, Marina Yusoff ${ }^{3,4}$, Emma Farquharson'1, Rauzah Hashim ${ }^{3}$

${ }^{1}$ Chemical and Materials Engineering Group, School of Engineering, University of Aberdeen. King's College, Aberdeen AB24 3UE, UK.

${ }^{2}$ Low Dimensional Material Research Center, Department of Physics, Faculty of Science, University of Malaya, 50603 Kuala Lumpur, Malaysia.

${ }^{3}$ Fundamental and Frontier Sciences in Nanostructure Self-Assembly Center, Department of Chemistry, Faculty of Science, University of Malaya, 50603 Kuala Lumpur, Malaysia.

${ }^{4}$ Faculty of Chemical Engineering, Universiti Teknologi MARA, 40450 Shah Alam, Malaysia.

*Corresponding author

Email address: fadhilah9413@uitm.edu.my

Phone number: +603-55438415 


\section{Introduction}

Interest in eco-friendly surfactants continues to increase as a way to prepare new formulations for cosmetic and biomedical applications. Glycolipids are very attractive candidates as non-ionic surfactants due to their amphiphilic character, resulting from their polar sugar head linked to the hydrophobic alkyl tail via a glycosidic bond. This enables the molecules to self-assemble by thermal and solvent effects, giving rise to thermotropic and lyotropic liquid crystalline behaviour that can be applied in a wide range of nano-and biotechnology areas $[1,2]$. Glycolipids can be advantageous to conventional ionic surfactants due to their biodegradable and non-toxic character, and possess the additional quality of being derived from common and cheap natural resources [2, 3]. Glycolipids can be found, for example, in cell membranes, and are known to be involved in cellular functions [4], making them suitable for targeted drug delivery systems [5, 6]. Alkyl polyglycosides, APG, are already commercially available as non-toxic surfactants used as microemulsions, detergents and cleaners [7].

Interestingly, mixtures of alkyl glycosides derived from palm oil, PO, and palm kernel oil, PKO, have been shown to be more efficient carriers than alkyl polyglycosides since the former have high drug loading and storage stability, and can potentially carry hydrophobic drug into deeper layers of the skin $[8,9]$. Palm oil is commonly used as a component in food and biological products due to its biocompatibility and superior emulsifying properties, and palm oil esters provide with excellent moisturizing capability and good skin compatibility, and are used in nanoemulsions of cosmeceutical products $[10,11]$. Palm kernel oil, on the other hand, represents over 5.5\% of fat from an oil palm (Elaeis guineensis) tree [12], and is readily available in tropical regions. Hydrogenated PKO, for example, is used in the formulation of lipid particles, i.e. nanostructured 
lipid carriers $[13,14]$, contributing to stabilize the particle and minimise undesired drug expulsion $[15]$.

Previous studies of glycoside surfactant systems employed common mono-/disaccharide such as glucose, galactose and maltose $[16,17,18,19,20,21,22,23,24,25]$. As part of a systematic study to develop new glycosides, we are now employing mannose, another naturally abundant sugar with many known therapeutic properties such as treatment of urinary tract infections [26, 27]. Mannose is also an epimer of glucose at C2 position and etymologically it is also derived from the word manna, which is commonly used as an energy source inspired from the biblical stories [28]. Therefore, we have synthesised a new natural product-based glycoside, bearing a mannose polar sugar head and using palm kernel oil as the lipid hydrophobic component, $\alpha$ ManPKO. Thus $\alpha \mathrm{ManPKO}$ is a mixture whose alkyl chains are those components of $\mathrm{PKO}$, the major ones are shown in Figure 1.

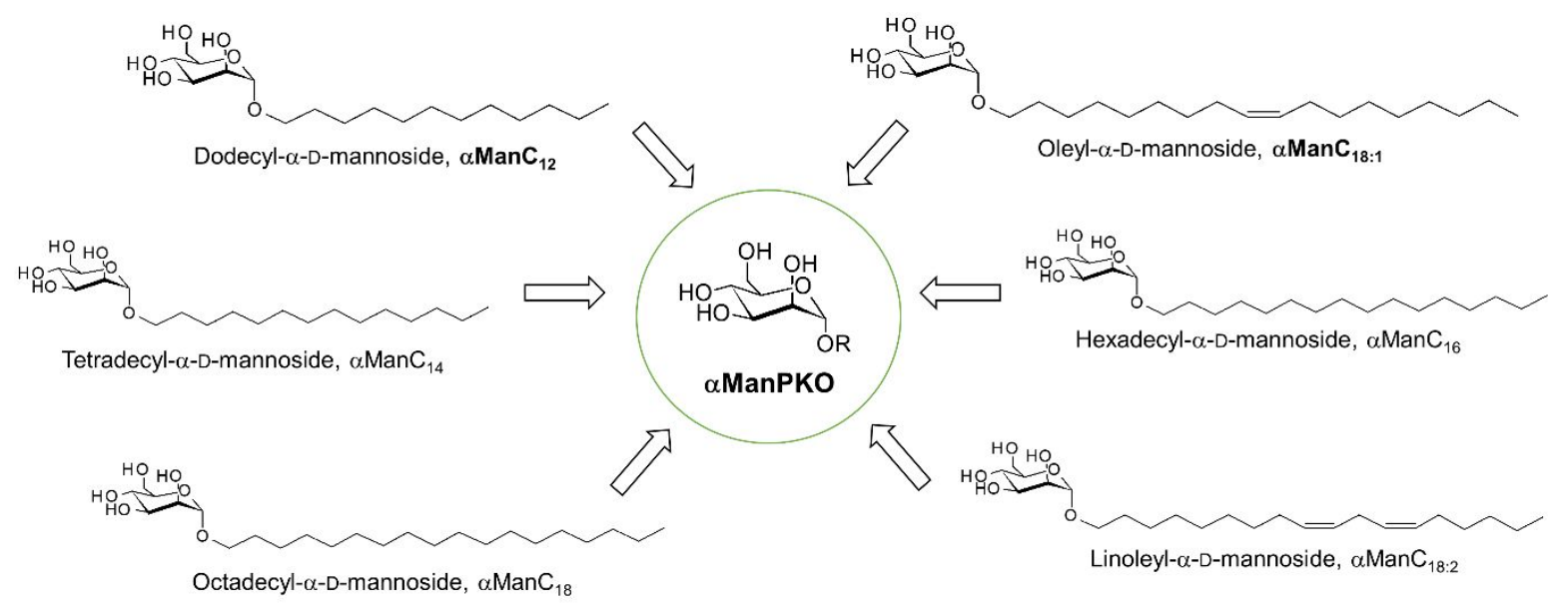

Figure 1. Chemical structures of major components in $\alpha \mathrm{ManPKO}$. The mannosides studied in the present work are $\alpha \mathrm{ManPKO}, \alpha \mathrm{ManC}_{12}$ and $\alpha \mathrm{ManC}_{18: 1}$ (bold text). 
We have carried out a detailed characterisation of the thermotropic behaviour, molecular interactions and mobility of $\alpha$ ManPKO. In addition, we have also prepared and characterised the two most abundant components in $\alpha$ ManPKO: the dodecyl (48\%) and oleyl, C18:1 (4\%) mannosides, $\alpha \mathrm{ManC}_{12}$, and $\alpha \mathrm{ManC}_{18: 1}$, respectively, for the sake of comparison.

The determination of the thermotropic properties of $\alpha$ ManPKO (a glycoside of a PKO mixture) will unveil its potential as a cheap natural-based surfactant from palm oil source and help understand how the subtle stereochemistry of mannose affects the properties of different glycosides, which in turn can be tuned to control their phases and end-applications.

\section{Experimental procedure}

\subsection{Materials preparation}

All chemicals used in the synthesis of $\alpha \mathrm{ManPKO}, \mathrm{D}(+)$-mannose monohydrate and boron trifluoride, $\mathrm{BF}_{3}$, were purchased from Sigma Aldrich and used without further purification. Palm kernel oil, PKO, was obtained from Golden Jomalina Food Industries Sdn. Bhd. (Malaysia), and the main components were lauric (49\%), myristic (16\%) and oleic $(8 \%)$ acids. Dodecanol and cis9-octadecen-1-ol, used for the synthesis of the pristine mannosides, were purchased from Merck. Solvents for synthesis were analytical grade and used without further purification.

The mannosides, $\alpha$ ManPKO, $\alpha \mathrm{ManC}_{12}$, and $\alpha \mathrm{ManC}_{18: 1}$, were synthesised using a three-steps method consisting of peracetylation, glycosylation, and finally deacetylation, as shown in Figure 2. Fatty acids of PKO were converted to $\mathrm{PKO}$ alcohol by reduction using lithium aluminium 
hydride, $\mathrm{LiAlH}_{4}$ [29]. Detailed synthetic procedures are provided in the Electronic Supplementary Information, ESI.
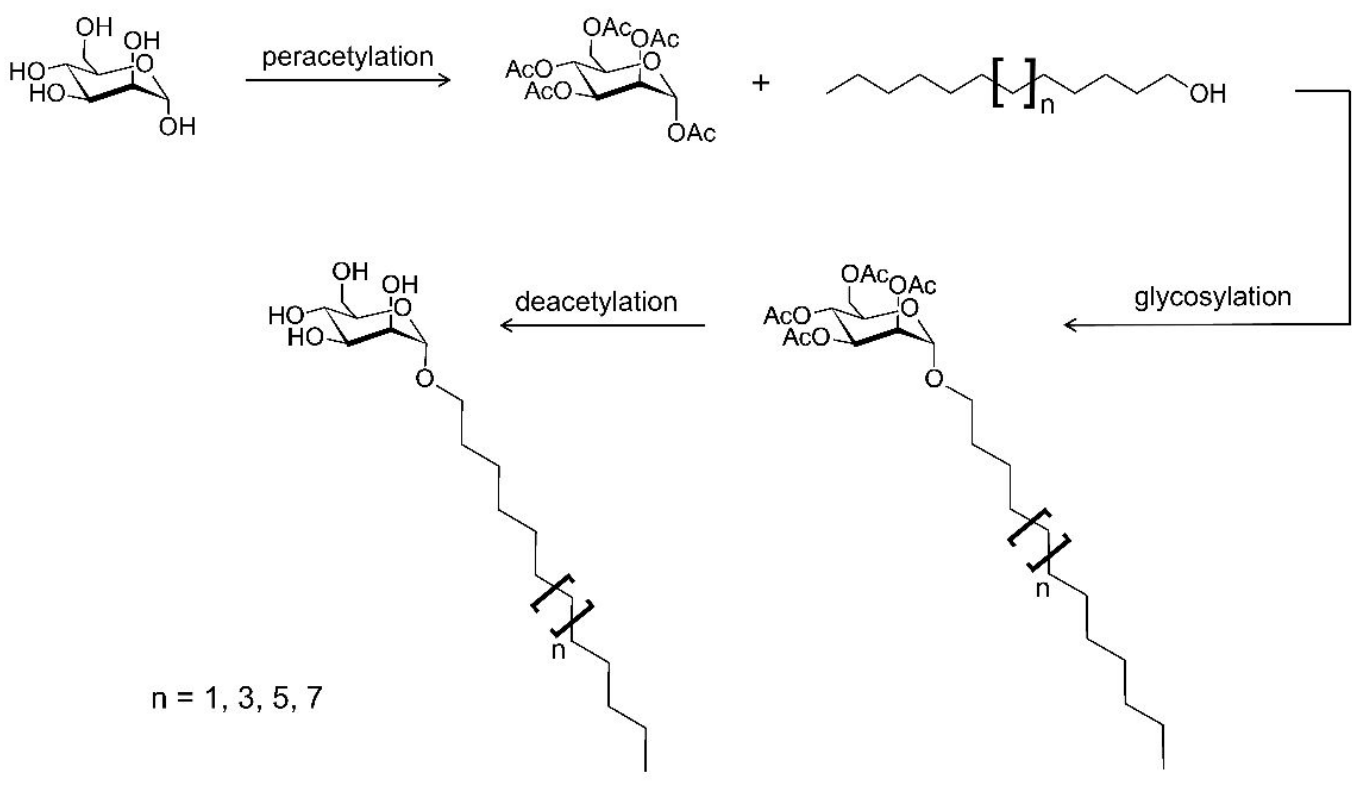

Figure 2. Synthesis route overview

The chemical structures of $\alpha$ ManPKO, $\alpha \mathrm{ManC}_{12}$ and $\alpha \mathrm{ManC}_{18: 1}$, were confirmed by ${ }^{1} \mathrm{H}-\mathrm{NMR}$ spectroscopy, using a Bruker NMR Systems spectrometer at $400 \mathrm{MHz}$. The spectra of all mannosides were obtained in methanol- $\mathrm{d}_{4}\left(\mathrm{CD}_{3} \mathrm{OD}\right)$ at room temperature.

МanPKO: $\delta=5.35(\mathrm{~m}, 0.1 \mathrm{H},-\mathrm{CH}=), 4.75(\mathrm{~d}, \alpha \mathrm{H}-1, \mathrm{~J}=3.6 \mathrm{~Hz}), 3.42-3.83(\mathrm{~m}$, bulk sugar signals), 2.03-2.06 (m, 0.25H, $\left.-\mathrm{CH}_{2}\right), 1.59-1.61\left(\mathrm{~m}, 2 \mathrm{H},-\mathrm{CH}_{2}-\right), 1.31\left(\mathrm{~m}, 21 \mathrm{H},-\mathrm{CH}_{2}-\right), 0.92(\mathrm{t}, 3 \mathrm{H}$, $\left.\mathrm{CH}_{3}\right)$.

$\alpha_{\operatorname{ManC}}{ }_{12} \delta=4.75(\mathrm{~d}, \alpha \mathrm{H}-1, \mathrm{~J}=3.6 \mathrm{~Hz}), 3.42-3.85$ (m, bulk sugar signals), 1.59-1.61 (m, 2H, $\left.\mathrm{CH}_{2^{-}}\right), 1.32\left(\mathrm{~m}, 20 \mathrm{H},-\mathrm{CH}_{2}^{-}\right), 0.92\left(\mathrm{t}, 3 \mathrm{H}, \mathrm{CH}_{3}\right)$. 
$\operatorname{\alpha ManC}_{18: 1} \delta=5.38(\mathrm{~m}, 2 \mathrm{H},-\mathrm{CH}=), 4.75(\mathrm{~d}, \alpha \mathrm{H}-1, \mathrm{~J}=3.6 \mathrm{~Hz}), 3.42-3.85$ (m, bulk sugar signals), 1.99-2.06 (m, 4H, $\left.-\mathrm{CH}_{2}\right), 1.59-1.61\left(\mathrm{~m}, 2 \mathrm{H},-\mathrm{CH}_{2^{-}}\right), 1.31\left(\mathrm{~m}, 23 \mathrm{H},-\mathrm{CH}_{2^{-}}\right), 0.92\left(\mathrm{t}, 3 \mathrm{H}, \mathrm{CH}_{3}\right)$.

The compositions of PKO alcohol were determined using a 450 GC/220 MS (Varian Inc. USA) gas chromatography system equipped with a 5975C inert MSD with triple-axis detector (Agilent Technology, USA). Operating conditions are described in the ESI following previous reports by Oborn [30].

\subsection{Phase diagram sample.}

Binary mixtures of $\alpha \mathrm{ManC}_{12}$ and $\alpha \mathrm{ManC}_{18: 1}$ were prepared by dissolving preweighed mannosides in methanol and the solvent slowly evaporated at $65^{\circ} \mathrm{C}$. The mixtures were further dried under vacuum at $65^{\circ} \mathrm{C}$ overnight.

\subsection{Characterisation techniques.}

The phase behaviour of the mannosides was determined by polarised optical microscopy, POM, and differential scanning calorimetry, DSC. The textural analysis was carried out by using an Olympus BX51 microscope equipped with cross-polarising filters coupled to a Mettler Toledo FP82HT hot stage. Samples were sandwiched between two glass slides, heated to their respective isotropic phases, and then cooled down to room temperature, at a rate of $10^{\circ} \mathrm{C} / \mathrm{min}$. Samples for DSC measurements were previously dried in a vacuum oven at $50^{\circ} \mathrm{C}$ for at least 3 hours over phosphorus pentoxide. Around $6 \mathrm{mg}$ of the samples were then placed in $40 \mu \mathrm{l}$-sized aluminium pans, and the heat flow measured using a Mettler Toledo differential scanning calorimeter 822e equipped with a Haake EK90/MT intercooler. Experiments were taken in subsequent heating and 
cooling cycles, ranging from $-40^{\circ} \mathrm{C}$ to above their respective clearing temperatures, at rates of \pm $5^{\circ} \mathrm{C} / \mathrm{min}$

The phase structures were analysed by Small/ Wide Angle X-Ray Scattering, SWAXS. Small angle X-ray scattering experiments were conducted using a SAXess, Anton Parr, equipped with a DX-Cu 12x0.45 SERFERT X-ray tube generating CuK $\alpha$ radiation at $\lambda=1.542 \AA$, attached to a TCS 150 temperature controller. Samples were placed inside a paste cell sample holder, which prior to measurements, was dried in a vacuum oven at least for $48 \mathrm{~h}$ at $30^{\circ} \mathrm{C}$. SWAXS scatterings were obtained on heating from $-10^{\circ} \mathrm{C}$ to $120^{\circ} \mathrm{C}$ after cooling from their respective clearing temperatures. All samples were thermally equilibrated for 5 minutes at each temperature before measurements. Data were analysed using the SAXSquant software package, and the liquid crystal phase was assigned using SGI software (Anton Paar).

Temperature-dependent Fourier-transform infrared spectroscopy, FT-IR, was carried out in order to study the intermolecular environment of the functional groups of $\alpha$ ManPKO. A Thermo Nicolet NEXUS 470 main bench (Thermo Scientific) was used, with the sample placed in a Linkam TMS93 hot stage unit for temperature control $( \pm 0.1 \mathrm{~K})$. The IR data were collected in transmittance mode and analysed with OMNIC (Thermo Scientific). The sample consisted of a dispersion of $\alpha \mathrm{ManPKO}$ into dry $\mathrm{KBr}(\sim 1 \%$ by wt. of $\alpha \mathrm{ManPKO})$ and was prepared by grinding both components into fine powder and further compression at $200 \mathrm{MPa}$ for at least 10 minutes, yielding a homogeneous disc of $10 \mathrm{~mm}$ diameter and around $1.5 \mathrm{~mm}$ thickness. A pristine $\mathrm{KBr}$ disc was also prepared and measured as the background, immediately prior to measure the sample. The $\alpha$ ManPKO disc was heated into its isotropic phase (above $150^{\circ} \mathrm{C}$ ), and the IR spectra were 
collected in isothermal steps, at $5^{\circ} \mathrm{C}$ intervals, when cooling to room temperature. Each measurement was taken after the temperature was stabilised for at least five minutes, to allow for thermal equilibration. Spectra were collected in the frequency range $4000-400 \mathrm{~cm}^{-1}$, with a 4 $\mathrm{cm}^{-1}$ resolution, and recorded as an average of 64 scans.

The molecular motions of $\alpha$ ManPKO were studied by broadband dielectric spectroscopy, BDS. A few milligrams of the sample in the isotropic phase were injected into empty liquid crystal cells by capillary action. The standard cells used were purchased from Instec, and consisted of two plane-parallel glass substrates with electrodes located on their inner sides prepared from indium tin oxide which had a surface area $\mathrm{S} \sim 10 \times 10 \mathrm{~mm}$, with low resistance $\sim 30 \Omega$ and a gap of $(9.0+$ 0.2) $\mu \mathrm{m}$. The electrode surfaces were treated in homeotropic (vertical) and planar alignment structures. The POM images of both alignments are shown in ESI (Figure ESI5). The dielectric measurement for both planar and homeotropic surface treated samples qualitatively show similar trend (refer to Figure ESI6). Thus, the dielectric measurement for the homeotropically aligned samples will be discussed. The complex dielectric measurements were carried out using an in home-developed dielectric spectrometer consisting of a charge amplifier and a digital dataacquisition system. The dielectric response was measured in frequency sweeps from $10 \mathrm{mHz}$ to $100 \mathrm{kHz}$, obtained at isothermal steps, on cooling from 140 to $25^{\circ} \mathrm{C}$. The results are expressed in terms of the complex permittivity, $\varepsilon^{*}$ :

$$
\varepsilon^{*}=\varepsilon^{\prime}-j \varepsilon^{\prime \prime}
$$

where $j$ is the imaginary unit, and $\varepsilon^{\prime}$ and $\varepsilon^{\prime \prime}$ the real and imaginary components of the permittivity, respectively.

\section{Results and discussion.}


The three mannosides ( $\alpha$ ManPKO, $\alpha \mathrm{ManC}_{12}, \alpha \mathrm{ManC}_{18: 1}$ ) were synthesised using a common synthetic procedure for glycosides $[16,31,32]$, with a yield of $\sim 80 \%$ for all the mannosides. During the glycosylation stage of a mannoside, only the $\alpha$-anomer is produced since the neighbouring group at the axial position sterically hinders the formation of the $\beta$-anomer [33]. The anomeric purity of $\sim 80 \%$ was assessed by ${ }^{1} \mathrm{H}-\mathrm{NMR}$.

For comparison, $\alpha \mathrm{ManC}_{12}$ and $\alpha \mathrm{ManC}_{18: 1}$ were synthesised since dodecyl and oleyl fatty acids are major components in $\mathrm{PKO}$ and hence in $\alpha \mathrm{ManPKO}$. However, other mannoside components may influence the thermotropic properties of $\alpha \mathrm{ManPKO}$, but this effect is assumed minor from the following argument. The trend of increasing $T_{c}$ is observed as the glycosides have longer alkyl chains, but, in case of monosaccharides, the maximum increment is reached between 12 to 14 carbons $[17,34]$. By considering that $\alpha \mathrm{ManC}_{12}$ has the shortest chain in $\alpha \mathrm{ManPKO}$, we assume the effect of other saturated mannosides would be minimum. On the other hand it is worth investigating the effect of a double bond as in $\alpha \mathrm{ManC}_{18: 1}$. The presence of a cis double bond significantly reduces the $T_{c}$, because the bent alkyl chain prevents van der Waals interactions and consequently reduce the packing efficiency [18]. Polyunsaturated components are also present in $\alpha$ ManPKO, however, it appears that the unsaturation effect on the $T_{c}$ becomes insignificant with additional double bonds as in the case of phospholipids [35].

\subsection{Phase behaviour and structure.}

The transitional properties of $\alpha \mathrm{ManPKO}, \alpha \mathrm{ManC}_{12}$ and $\alpha \mathrm{ManC}_{18: 1}$ are listed in Table 1, together with some values obtained by other authors.

On cooling $\alpha \mathrm{ManPKO}$ from the isotropic melt under the polarised microscope, battonêtes appear and further coalesce into a focal conic fan texture below $c a .147^{\circ} \mathrm{C}$, which flashes upon pressure, 
characteristic of smectic A phases. The sample remains fluid over a broad temperature range and the birefringence persists on cooling to room temperature, when thermal fluctuations cease. This suggests that the liquid crystal phase vitrifies at sufficiently low temperatures, similarly to other monoalkylated glycosides $[21,36,37]$. On heating, $\alpha$ ManPKO remains non-fluid below its clearing point, $\mathrm{T}_{\mathrm{c}}=147^{\circ} \mathrm{C}$, indicating the monotropic character of the liquid crystal phase. Figure 3, on the other hand, shows the DSC thermograms of $\alpha$ ManPKO, obtained on heating. There are different thermal events in excellent agreement with our microscope observations, and the corresponding parameters are also summarised in Table 1. A broad first order transition is visible with a peak maximum at $\mathrm{T}_{\mathrm{c}}=146^{\circ} \mathrm{C}$, associated to the smectic to isotropic phase transition, together with a glass transition at slightly above $\mathrm{T} \sim 0^{\circ} \mathrm{C}$. These results are reproducible after subsequent heating and cooling cycles, and it is worth noting that during these thermal programmes we did not observed signs of decomposition originating from double bonds oxidation [38, 39].

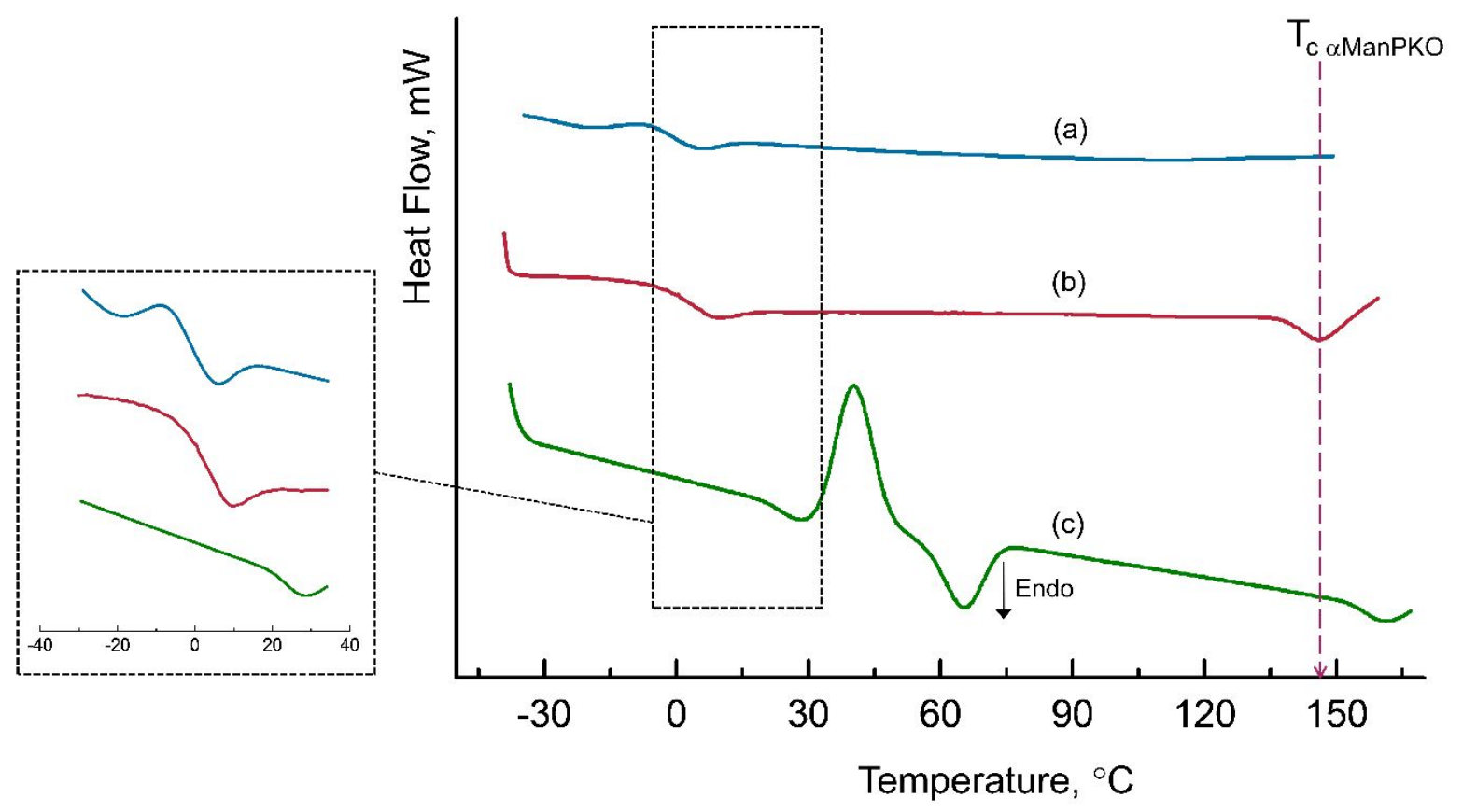


Figure 3. DSC traces of (a) $\alpha \mathrm{ManC}_{18: 1}$, (b) $\alpha \mathrm{ManPKO}$, and (c) $\alpha \mathrm{ManC}_{12}$ corresponding to the second heating scan. The inset highlights the $\mathrm{T}_{\mathrm{g}}$ of the mannosides. In these graphs, curves have been rescaled and shifted along the y-axis. The dotted arrow corresponds to the clearing temperature $\left(\mathrm{T}_{\mathrm{c}}=146^{\circ} \mathrm{C}\right)$ for $\alpha \mathrm{ManPKO}$.

Both $\alpha \mathrm{ManC}_{12}$ and $\alpha \mathrm{ManC}_{18: 1}$ also exhibit monotropic smectic A phases, according to our POM observations, and the corresponding DSC thermograms in Figure 3 are also consistent with such assignments. The values of the associated thermal events are included in Table 1. The smectic to isotropic transition observed by POM and DSC for $\alpha \mathrm{ManC}_{12}, \mathrm{~T}_{\mathrm{c}} \sim 162^{\circ} \mathrm{C}$, is in excellent agreement with the values reported by Vill [16], Brown [40] and Zhang [34]. By DSC, however, we also observe for $\alpha \mathrm{ManC}_{12}$, a large melting peak at around $\mathrm{T}_{\mathrm{m}}=65^{\circ} \mathrm{C}$, together with a glass transition at $\mathrm{T}_{\mathrm{g}} \sim 25^{\circ} \mathrm{C}$ (see inset in Figure 3 and Table 1).

Table 1. Transition temperatures of $\alpha \mathrm{ManPKO}, \alpha \mathrm{ManC}_{12}$ and $\alpha \mathrm{ManC}_{18: 1}$ obtained by polarised optical microscopy, POM and differential scanning calorimetry, DSC. $\mathrm{T}_{\mathrm{g}}$ denotes glass transition temperature, $T_{m}$, and $T_{c}$, are the melting and clearing temperatures, respectively; $\Delta H_{m}$ is the crystal to smectic enthalpy and $\Delta \mathrm{H}_{\mathrm{c}}$, smectic to isotropic enthalpy. In bold, values obtained as part of the present study.

\begin{tabular}{|c|c|c|c|c|c|c|c|c|}
\hline \multirow[b]{2}{*}{ Compound } & \multicolumn{2}{|c|}{ POM } & \multicolumn{5}{|c|}{ DSC } & \multirow[b]{2}{*}{ Ref. } \\
\hline & $\begin{array}{l}\mathrm{T}_{\mathrm{m}}, \\
\left({ }^{\circ} \mathrm{C}\right)\end{array}$ & $\begin{array}{l}\mathrm{T}_{\mathrm{c}}, \\
\left({ }^{\circ} \mathrm{C}\right)\end{array}$ & $\begin{array}{c}\mathrm{T}_{\mathrm{g}}, \\
\left({ }^{\circ} \mathrm{C}\right)\end{array}$ & $\begin{array}{l}\mathrm{T}_{\mathrm{m}}, \\
\left({ }^{\circ} \mathrm{C}\right)\end{array}$ & $\begin{array}{c}\Delta \mathrm{H}_{\mathrm{c}} \\
\left(\mathrm{kJ} \cdot \mathrm{mol}^{-1}\right)\end{array}$ & $\begin{array}{l}\mathrm{T}_{\mathrm{c}}, \\
\left({ }^{\circ} \mathrm{C}\right)\end{array}$ & $\begin{array}{c}\Delta \mathrm{H}_{\mathrm{c}} \\
\left(\mathrm{kJ} \cdot \mathrm{mol}^{-1}\right)\end{array}$ & \\
\hline$\alpha$ ManPKO & - & 147 & $\sim 0$ & - & - & 146 & 1.4 & $\begin{array}{c}\text { Current } \\
\text { work }\end{array}$ \\
\hline \multirow[t]{4}{*}{$\alpha \operatorname{ManC}_{12}$} & - & 162 & 25 & 65 & 31.5 & 161 & 2.3 & $\begin{array}{c}\text { Current } \\
\text { work }\end{array}$ \\
\hline & 74 & 162 & & & & & & {$[16]$} \\
\hline & $73-75$ & $164-165$ & & & & & & [40] \\
\hline & 67 & 157 & & & & & & [41] \\
\hline
\end{tabular}




\begin{tabular}{|c|c|c|c|c|c|c|c|c|}
\hline & & & & 74 & 37.0 & 160 & 2.2 & [34] \\
\hline$\alpha \operatorname{ManC}_{18: 1}$ & - & 140 & $\sim 0$ & - & - & - & - & $\begin{array}{c}\text { Current } \\
\text { work }\end{array}$ \\
\hline$\alpha \mathrm{ManOC}_{6} \mathrm{C}_{2}$ & - & 145 & -13 & - & - & 143 & 2.5 & {$[32]$} \\
\hline$\alpha \mathrm{ManOC}_{8} \mathrm{C}_{4}$ & - & 120 & -25 & - & - & 120 & - & {$[32]$} \\
\hline$\alpha \mathrm{ManOC}_{10} \mathrm{C}_{6}$ & - & 51 & -1 & 20 & 2.2 & 48 & 0.3 & {$[32]$} \\
\hline$\alpha \mathrm{ManOC}_{12} \mathrm{C}_{8}$ & - & 40 & -2 & 17 & 3.0 & 35 & 0.3 & {$[32]$} \\
\hline \multirow[t]{2}{*}{$\alpha \mathrm{GluC}_{12}^{\mathrm{a}}$} & 82 & 148 & - & 80 & 55.2 & 147 & 2.2 & [19] \\
\hline & 77 & 151 & - & - & - & - & - & [17] \\
\hline \multirow[t]{2}{*}{$\beta \mathrm{GluC}_{12}{ }^{\mathrm{b}}$} & 81 & 146 & - & 78 & 17.9 & 149 & 2.3 & [19] \\
\hline & - & & 12 & 77 & 20.8 & 144 & 1.3 & {$[21]$} \\
\hline$\beta_{\text {GluC }}{ }_{18: 1}^{c}$ & - & 126 & - & - & - & - & - & {$[17]$} \\
\hline$\alpha \mathrm{GalC}_{12}{ }^{\mathrm{d}}$ & 77 & 140 & - & - & - & - & - & {$[23]$} \\
\hline$\beta \mathrm{GalC}_{12}{ }^{\mathrm{e}}$ & 99 & 166 & - & - & - & - & - & [17] \\
\hline$\beta \mathrm{GalC}_{18: 1}{ }^{\mathrm{f}}$ & 81 & 145 & - & - & - & - & - & {$[17]$} \\
\hline
\end{tabular}

${ }^{\mathrm{a}}$ Dodecyl- $\alpha$-D-glucoside, ${ }^{\mathrm{b}}$ Dodecyl- $\beta$-D-glucoside ${ }^{\mathrm{c}}$ Oleyl- $\beta$-D-glucoside, ${ }^{\mathrm{d}}$ Dodecyl- $\alpha$-D-galactoside, ${ }^{\mathrm{e}}$ Dodecyl- $\beta$-D-galactoside, ${ }^{f}$ Oleyl- $\beta$-D-galactoside

The DSC thermogram obtained on cooling $\alpha \mathrm{ManC}_{18: 1}$, on the other hand, displays a broad first order transition at high temperatures, together with a prominent glass transition at $\mathrm{T}_{\mathrm{g}} \sim 0^{\circ} \mathrm{C}$. To the best of our knowledge, this is the first report of this compound, and the results evidence the effect of unsaturation on the phase behaviour of glycosides. The presence of long alkyl chains in C18:1 lowers its $\mathrm{T}_{\mathrm{c}}$ compared to that of $\alpha \mathrm{ManC}_{12}$, due to a back-folding effect of the chain that ultimately narrows the smectic phase $[42,43]$. In addition, the kink in the alkyl chain at the unsaturation in C18:1 must reduce their packing efficiency and prevent crystallisation, and its presence in PKO may ultimately promote vitrification of the smectic phase of $\alpha$ ManPKO. To verify this finding, we have constructed a binary phase diagram of $\alpha \mathrm{ManC}_{12}$ and $\alpha \mathrm{ManC}_{18: 1}$ (Figure 4). From the phase diagram, increasing the amount of $\alpha \mathrm{ManC}_{18: 1}$, results in lowering 


\section{the glass transition $\mathrm{T}_{\mathrm{g}}$ of the binary mixture to about $\mathrm{T}_{\mathrm{g}} \sim 0^{\circ} \mathrm{C}$, which is similar to that of $\alpha \mathrm{ManC}_{18: 1}$.}

The $\mathrm{T}_{\mathrm{c}}$ of the mixture also decreases slightly as the unsaturated $\alpha \mathrm{ManC}_{18: 1}$ is added. Furthermore, $\alpha \mathrm{ManC}_{12}$ crystallisation ( $\left.\mathrm{T}_{\mathrm{m}}\right)$ is suppressed when the content of $\alpha \mathrm{ManC}_{18:} 1$ exceeds $4 \%$, which supports our results on $\alpha \mathrm{ManPKO}$ (Figure 3(b)). All these results are in excellent agreement with similar findings for glucosides and galactosides, which are also gathered in Table 1 [16, 17, 19]. The transitions temperatures of Guerbet branched chain mannosides [32] are also listed in Table 1, and their glass transitions $\left(\mathrm{T}_{\mathrm{g}}\right.$ 's) are similar to that of $\alpha \mathrm{ManC}_{18: 1}$ and lower compared to that of $\alpha \mathrm{ManC}_{12}$. This shows that branching of the alkyl chain has comparable effect as the presence of unsaturation.

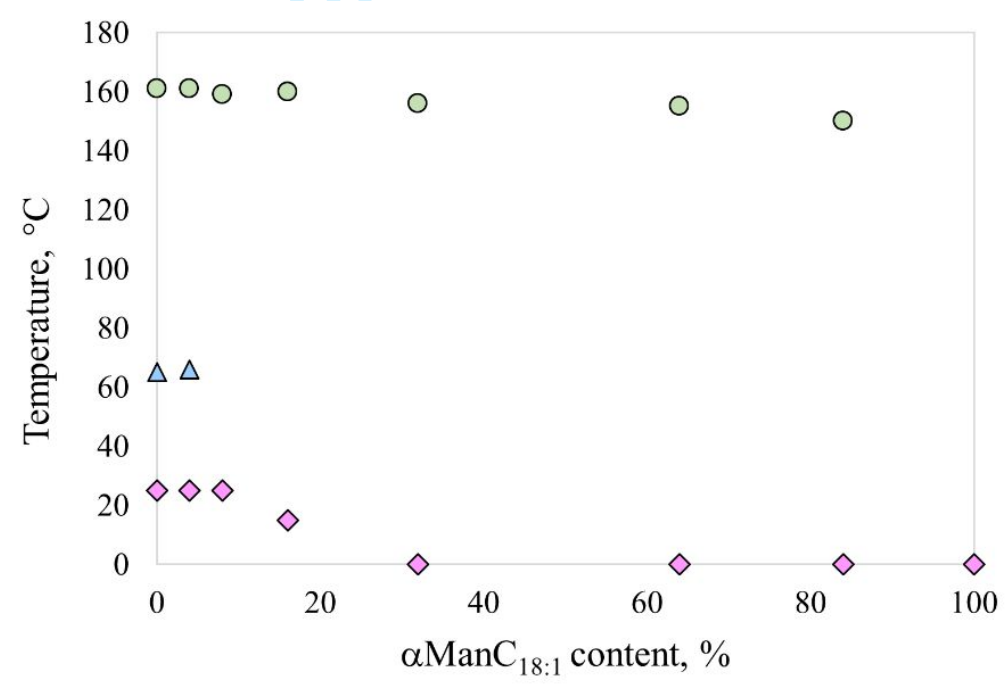

Figure 4. Phase diagram constructed for binary mixtures of $\alpha \mathrm{ManC}_{12}$ and $\alpha \mathrm{ManC}_{18: 1}$. The diamonds represent $T_{g}$, triangles represent $T_{m}$ and circles, $T_{c}$.

The SWAXS scattering patterns of $\alpha \mathrm{ManPKO}, \alpha \mathrm{ManC}_{12}$ and $\alpha \mathrm{ManC}_{18: 1}$, collected at $\mathrm{T}=120^{\circ} \mathrm{C}$ are shown in Figure 5, after cooling from their isotropic phases to $-10^{\circ} \mathrm{C}$ then subsequent heating to $25^{\circ} \mathrm{C}$ and $120^{\circ} \mathrm{C}$. These patterns are consistent with the formation of smectic phases. The scatterings of $\alpha$ ManPKO contains reflections at $d_{l}=30.8 \AA$ and $d_{2}=15.4 \AA$, which can be associated 
to first and second order diffractions of the smectic layer periodicities, see Table 2. A broad diffuse reflection is also visible at the wide-angle region, corresponding to the alkyl chain distances, with $d_{2}=5.2 \AA$.

We have estimated an averaged molecular length of $l \sim 23 \AA$ for $\alpha$ ManPKO, considering that $\alpha \mathrm{ManC}_{12}$ is its major component and the alkyl chains are found in all-trans configuration [44]. This suggests that $\alpha \mathrm{ManPKO}$ forms smectic bilayers with certain degree of interdigitation of the alkyl chains since $l<d_{1}<2 l$. However, the scattering pattern of $\alpha \mathrm{ManC}_{12}$, as well as the corresponding reflections, $d_{1}, d_{2}$ and $d_{3}$, are much lower than those of $\alpha$ ManPKO (Figure 4). At three temperatures $\left(-10,25\right.$ and $\left.120^{\circ} \mathrm{C}\right), d$ - $\alpha$ ManPKO lies in between those values of $\alpha \mathrm{ManC}_{12}$ and $\alpha \mathrm{ManC}_{18: 1}$. Surprisingly, $d$ - $\alpha$ ManPKO appears to be closer to $d$ - $\alpha \mathrm{ManC}_{18: 1}$, even though $\alpha \mathrm{ManC}_{12}$ is the major component of $\alpha \mathrm{ManPKO}$.

Unsaturation also promotes the extension of the smectic phase in $\alpha$ ManPKO in a broad temperature range above $\mathrm{T}_{\mathrm{g}}$, unlike $\alpha \mathrm{ManC}_{12}$, whose smectic phase is only observed above $\mathrm{T}_{\mathrm{m}}$. Another distinct phase is observed below $\mathrm{T}_{\mathrm{m}}$. This phase is non-crystalline since its scattering pattern lacks sharp reflections in the wide-angle region, and instead several diffused peaks are observed, with the main one at $4.1 \AA\left(\mathrm{T}=25^{\circ} \mathrm{C}\right)$. This prominent peak is well-defined compared to the broad peak observed at $5.2 \AA\left(\mathrm{T}=120^{\circ} \mathrm{C}\right)$ suggesting the formation of ordered lamellar phase. This result concurs with that of Zhang et al. obtained at $25^{\circ} \mathrm{C}$ for dodecyl mannoside [34]. Ordered lamellar phases have also been reported for dodecyl maltoside by Ericsson et al. [36]. 
(a)

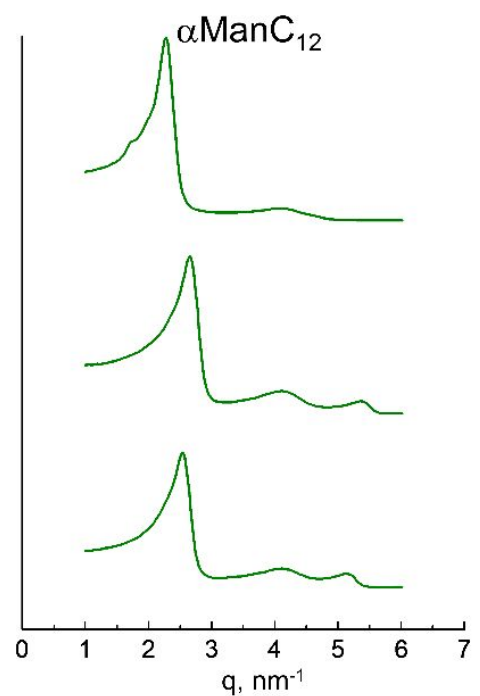

(b)

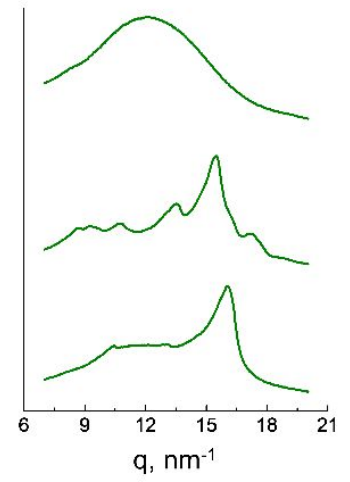

$\alpha$ ManPKO
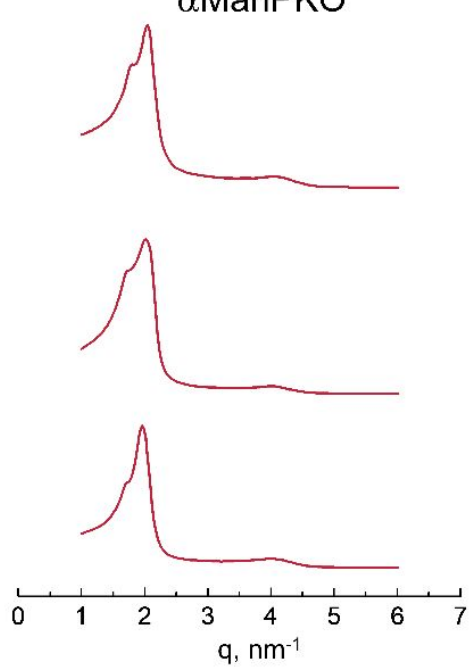

$\mathrm{q}, \mathrm{nm}^{-1}$

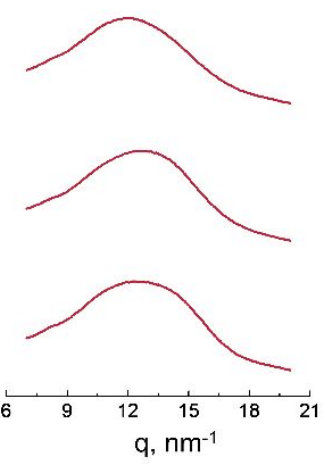

$\alpha \operatorname{ManC}_{18: 1}$
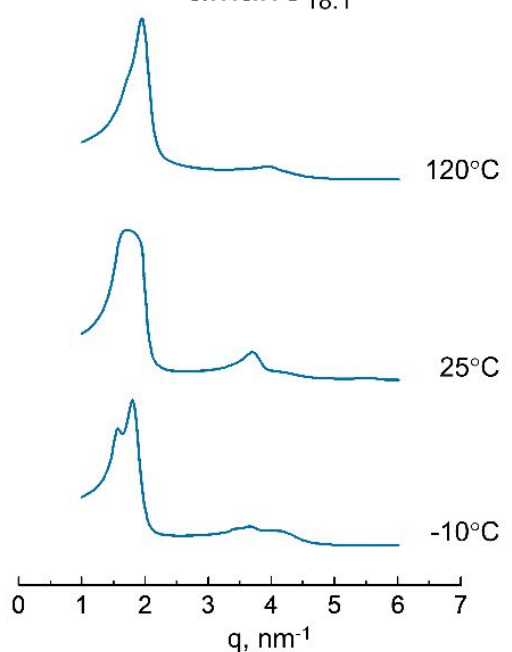

$-10^{\circ} \mathrm{C}$

Figure 5. Small/wide angle x-ray scattering patterns, SWAXS, obtained for $\alpha$ ManPKO, $\alpha \mathrm{ManC}_{12}$ and $\alpha \mathrm{ManC}_{18: 1}$ on heating, $\mathrm{T}=-10,25$, and $120^{\circ} \mathrm{C}$. The small angle $\mathrm{x}$-ray scatterings are shown in (a) while the wide-angle regions are shown in (b). Curves are arbitrarily shifted along the y-axis.

Interestingly, when heating $\alpha$ ManPKO from -10 to $120^{\circ} \mathrm{C}$, a shoulder to the primary peak was consistently observed and by deconvolution, a lower $\mathrm{q}$ is obtained at $1.8 \mathrm{~nm}^{-1}$. This secondary peak suggests the co-existence of smectic phases in $\alpha$ ManPKO. Since this signal is present in $\alpha \mathrm{ManC}_{18: 1}$, but is not visible in $\alpha \mathrm{ManC}_{12}$, our results further evidence the strong influence of the unsaturated components on the liquid crystalline structure of $\alpha$ ManPKO. Table 2 shows the $d$ spacings of the three mannosides. 


\subsection{Study of intermolecular interactions and hydrogen bonding.}

We now investigate the intermolecular interactions in $\alpha$ ManPKO by Fourier-transform infrared spectroscopy, FT-IR. Figure 6 shows the FT-IR spectra of $\alpha$ ManPKO, obtained at different temperatures on cooling from the isotropic phase, which contain bands associated to different functional groups [42]. There are some IR regions that undergo notable variations with temperature, which are reversible and reproducible on subsequent heating and cooling cycles.

More particularly, the increase of the higher frequency end of the C-H bending region, $v(\delta) \sim 1467$ $\mathrm{cm}^{-1}$, and the simultaneous decrease of the lower frequency end, $v(\delta) \sim 1440-1400 \mathrm{~cm}^{-1}$, denotes the formation of stronger van der Waals interactions on cooling through the liquid crystal range. These may result from a more efficient packing between alkyl chains of molecules located at the same layer when interdigitation decreases on cooling, see again Table 2 [28]. 


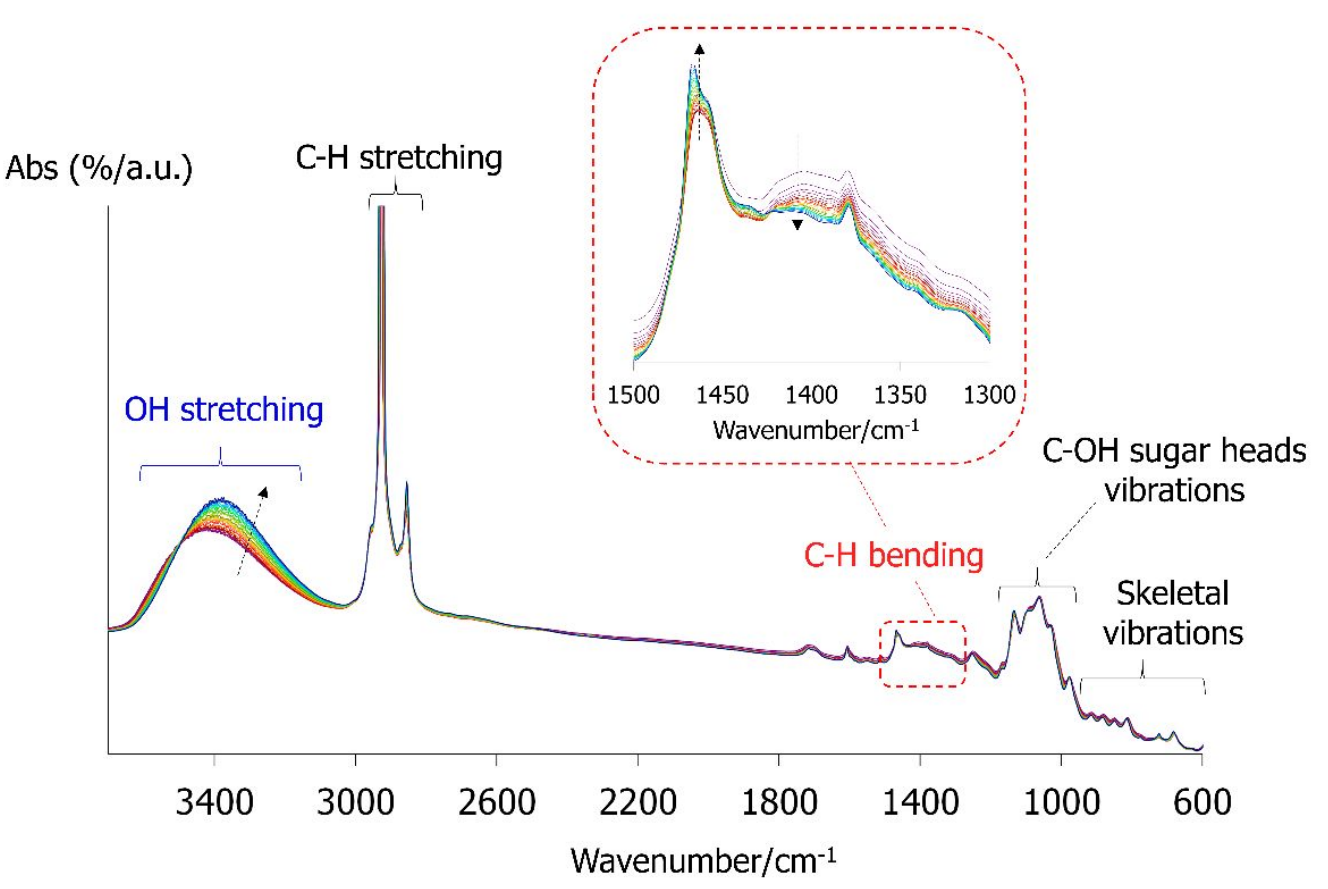

Figure 6. Temperature dependence of the FT-IR spectra of $\alpha$ ManPKO, highlighting the O$\mathrm{H}$ stretching, st., and $\mathrm{C}-\mathrm{H}$ bending, $\delta$. regions. Arrows indicate direction on cooling.

If we now turn our attention to the IR vibrations associated to the polar heads of $\alpha$ ManPKO, the O-H stretching band in Figure 6 extends towards relatively low wavenumbers, in a broad range of frequencies, $v(s t$. $) ~ 3600-3000 \mathrm{~cm}^{-1}$, denoting the formation of hydrogen bonding in this sample $[45,46,47,48]$. The shift of this band towards lower frequencies on cooling, moreover, indicates the tendency to form stronger interactions within the hydrophilic domains of $\alpha \mathrm{ManPKO}$, due to the reconstruction of hydrogen bonds at lower temperatures. The maxima of the $\mathrm{O}-\mathrm{H}$ st. bands can be obtained from Figure 6, and the frequency values, $v_{\mathrm{OH}-\mathrm{max}}$, are plotted as a function of the temperature in Figure 7. We have then calculated the wavenumber-temperature coefficient, WTC [49], as the slope in this graph. Our current value, $\mathrm{WTC}=0.267 \mathrm{~cm}^{-1} / \mathrm{K}$, falls within the range of 
other sugars [49] and glycosides [42, 50] measured in their glassy states, but it is smaller than values typically obtained in liquid crystal phases. This indicates that the hydrogen bond network of $\alpha$ ManPKO has low thermal sensitivity, and, in terms of Angell's strength and fragility [51, 52, 53], is consistent with the lack of crystallisation.

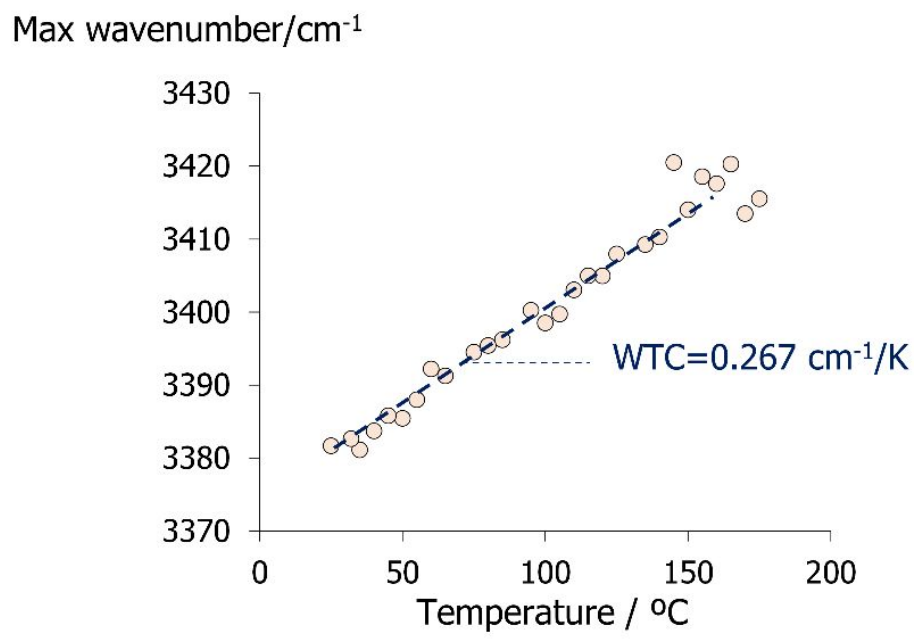

Figure 7. Temperature dependence of the $\mathrm{O}-\mathrm{H}$ stretching band maximum, $v_{\mathrm{OH}-m a x}$ obtained on cooling from the isotropic melt, showing the calculation of the wavenumber-temperature coefficient, WTC.

The broad profiles of the $\mathrm{OH}$ st. bands in Figure 6 are typical of sugars and glycosides, which have a distribution of hydroxyl groups found in different intermolecular environments [54]. Spectroscopic assignation to particular hydroxyl groups within the polar heads is complicated in glycosides, due to the large number of interactions occurring in the polar domains of their smectic layers $[55,56,57]$, which may comprise intramolecular, and intermolecular inter- and intra-layer interactions, see Figure $8[41,58]$. Hence, as an attempt to further discriminate the nature and strength of the different hydrogen bonds in $\alpha$ ManPKO, we have fit the $3600-3000 \mathrm{~cm}^{-1}$ region to 
three Gaussian peaks that account for different hydroxyl groups: free, at high frequencies, $v>3500$ $\mathrm{cm}^{-1}$, and weakly and strongly hydrogen bonded, $v_{\max } \sim 3410 \mathrm{~cm}^{-1}$ and $v_{\max } \sim 3250 \mathrm{~cm}^{-1}$, respectively, see Figure 9(a). We calculated the areas of these individual bands and normalised them respect to the overall IR region, and we show the results as a function of the temperature in Figure 9(b).

(a)

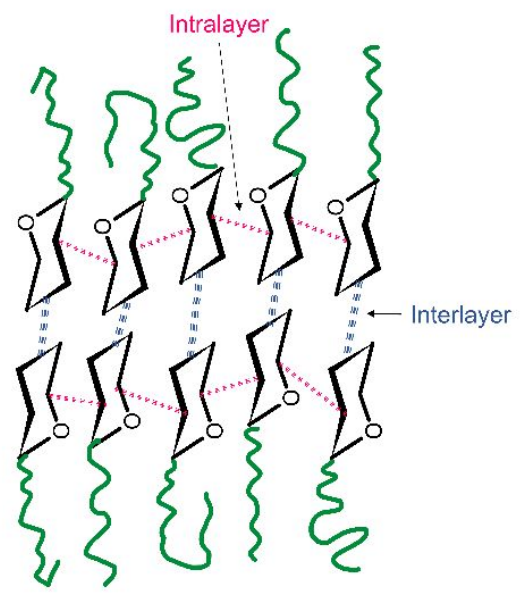

(b)

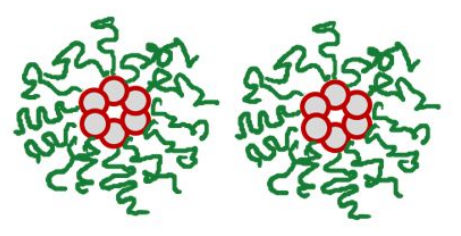

Figure 8. (a) Schematic model of smectic A phase for $\alpha \mathrm{ManPKO}$, showing intermolecular, intramolecular, interlayer and intralayer hydrogen bonds; (b) model of isotropic micellar phase. 
(a)

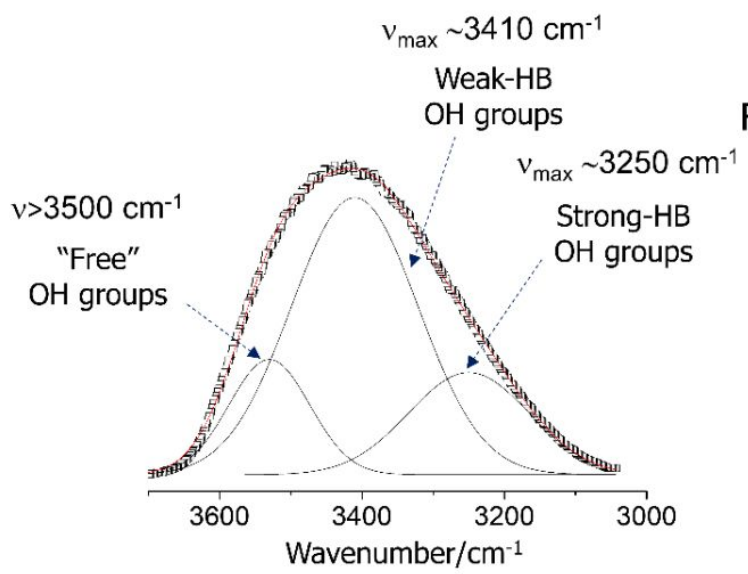

(b)

Relative area / $\%$

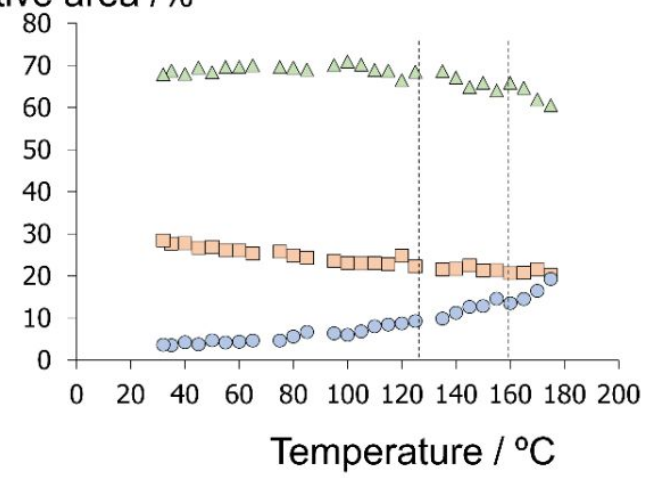

Figure 9. Deconvolution of the $\mathrm{OH}$ stretching region to three Gaussian peaks: (a) Example of the fitting at $\mathrm{T}=160^{\circ} \mathrm{C}$; (b) relative peak areas for the different individual, including $\bigcirc$ free $\mathrm{OH}$ groups $\left(v_{\max } \sim 3500 \mathrm{~cm}^{-1}\right)$, and $\mathrm{OH}$ groups forming: $\triangle$ weak hydrogen bonds $\left(v_{\max } \sim\right.$ $\left.3410 \mathrm{~cm}^{-1}\right)$, and $\square$ strong hydrogen bonds, $\mathrm{HB}\left(v_{\max } \sim 3250 \mathrm{~cm}^{-1}\right)$.

As expected, the relative contribution from free hydroxyl groups, band at $v_{\max } \sim 3530 \mathrm{~cm}^{-1}$, decreases on cooling, indicating the establishment of hydrogen bonds. On the other hand, we discard the presence of intramolecular hydrogen bonds in $\alpha \mathrm{ManPKO}$, according to calculations performed using the atoms in molecules theory, AIM [59]. The IR peaks below $3500 \mathrm{~cm}^{-1}$ must then correspond to $\mathrm{OH}$ groups forming intermolecular hydrogen bonds within (intra) and between (inter) smectic layers of $\alpha \mathrm{ManPKO}$ [60]. Interestingly, hydrogen bondings are still extensive in the isotropic melt, suggesting the formation of aggregates that persist at high temperatures, like micellar phases Figure 8(b) [42]. Weak hydrogen bonds, $v_{\max } \sim 3410 \mathrm{~cm}^{-1}$, are predominant in the whole temperature range, and are further favoured when entering the liquid crystal range of $\alpha$ ManPKO, below $\mathrm{T}_{\mathrm{c}}$. This fact can be explained by the presence of less interlayer interactions in mannose derivatives than expected, and is consistent with the model proposed by Chong et al. 
[58]. Whilst weak hydrogen bonds seem to contribute to form the bilayer structure and promote liquid crystallinity of $\alpha \mathrm{ManPKO}$, the strong hydrogen bonds may restrict motions needed for crystallisation, contributing to vitrify the smectic phase at low temperatures, which again is consistent with our DSC observations.

\subsection{Molecular mobility: dielectric studies}

We have just seen how the presence of polarisable OH groups makes $\alpha$ ManPKO highly sensitive to the intermolecular environment, and ultimately determines its phase behaviour. We now investigate the molecular mobility (dynamics) by determining the dielectric response of $\alpha \mathrm{ManPKO}$ at different temperatures, which may provide with information of structural effects from intermolecular forces. Thus, the isothermal real, $\varepsilon$ ', and imaginary, $\varepsilon$ ', permittivity spectra of aManPKO, were obtained in the frequency domain above its glass transition, $T_{\mathrm{g}}$, and the results are presented in Figure 10(a) and 10(b), respectively. The sharp increase in the $\varepsilon$ "' values at the low frequency end in Figure 10(b) denotes $d c$ conductivity, due to the translational motions of the sum of ionic impurities and intermolecular proton hopping.

At higher frequencies, several relaxations are visible, which are more evident from the $\tan \delta$ response of $\alpha \mathrm{ManPKO}$ depicted at $1 \mathrm{kHz}$ in Figure 11. The process at higher frequencies (and lower temperatures) is assigned to the so-called $\alpha$-relaxation, associated to the cooperative motion of the glycoside molecules, which is well defined in many saccharides (pentopyranoses, hexopyranoses, glucose, maltose, etc.). Generally, for carbohydrates, the peak in tan $\delta$ observed at a temperature typically $20^{\circ} \mathrm{C}$ above the $\mathrm{T}_{\mathrm{g}}$ is attributed to the dielectric $\alpha$-relaxation. The peak maximum for this relaxation in $\alpha \mathrm{ManPKO}$ is obtained at $\partial \tan \delta / \partial T=0$, giving a value of $\mathrm{T}_{\alpha} \sim$ 
$29^{\circ} \mathrm{C}$. Since $T_{\mathrm{g}}=0.75{ }^{\circ} \mathrm{C}$, according to our DSC measurement, the $\mathrm{T}_{\mathrm{g}} / \mathrm{T}_{\alpha}$ ratio is calculated as $\sim 1.11$. Interestingly, this value is much higher than that reported for dry D-mannose, which is only 0.93 [61]. This is probably because the $\mathrm{T}_{\mathrm{g}}$ of $\mathrm{D}$-mannose (glassy phase sugar) is distinct to that of aManPKO, since this latter forms a lamellar glass.
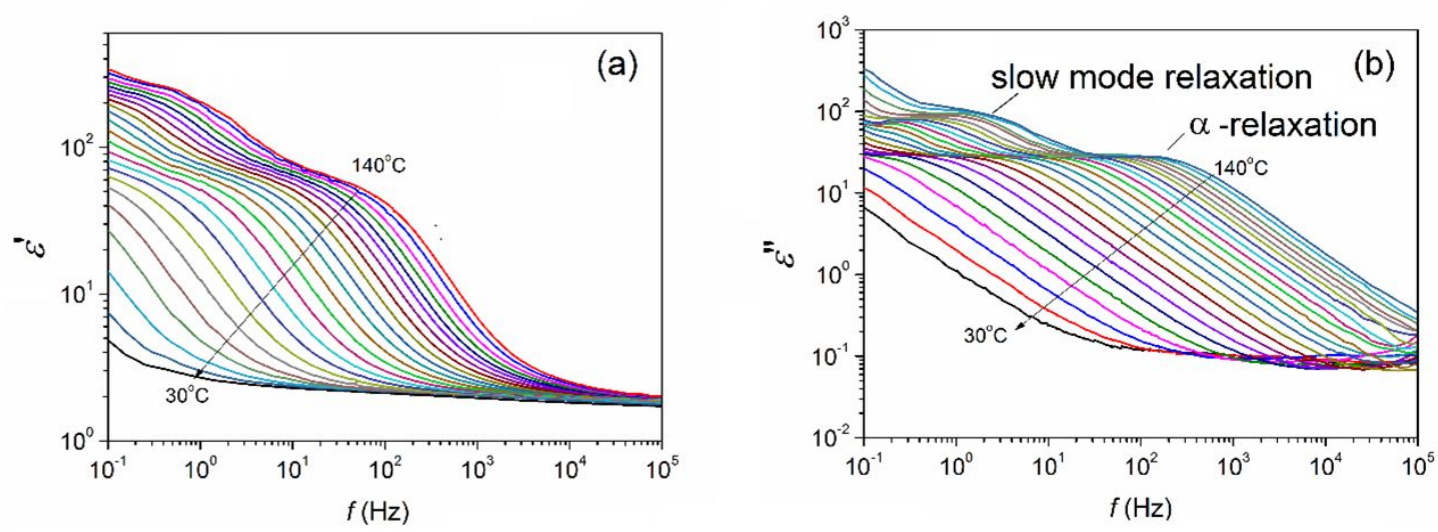

Figure 10. The temperature and frequency dependence of the (a) real and (b) imaginary permittivity of $\alpha$ ManPKO. 


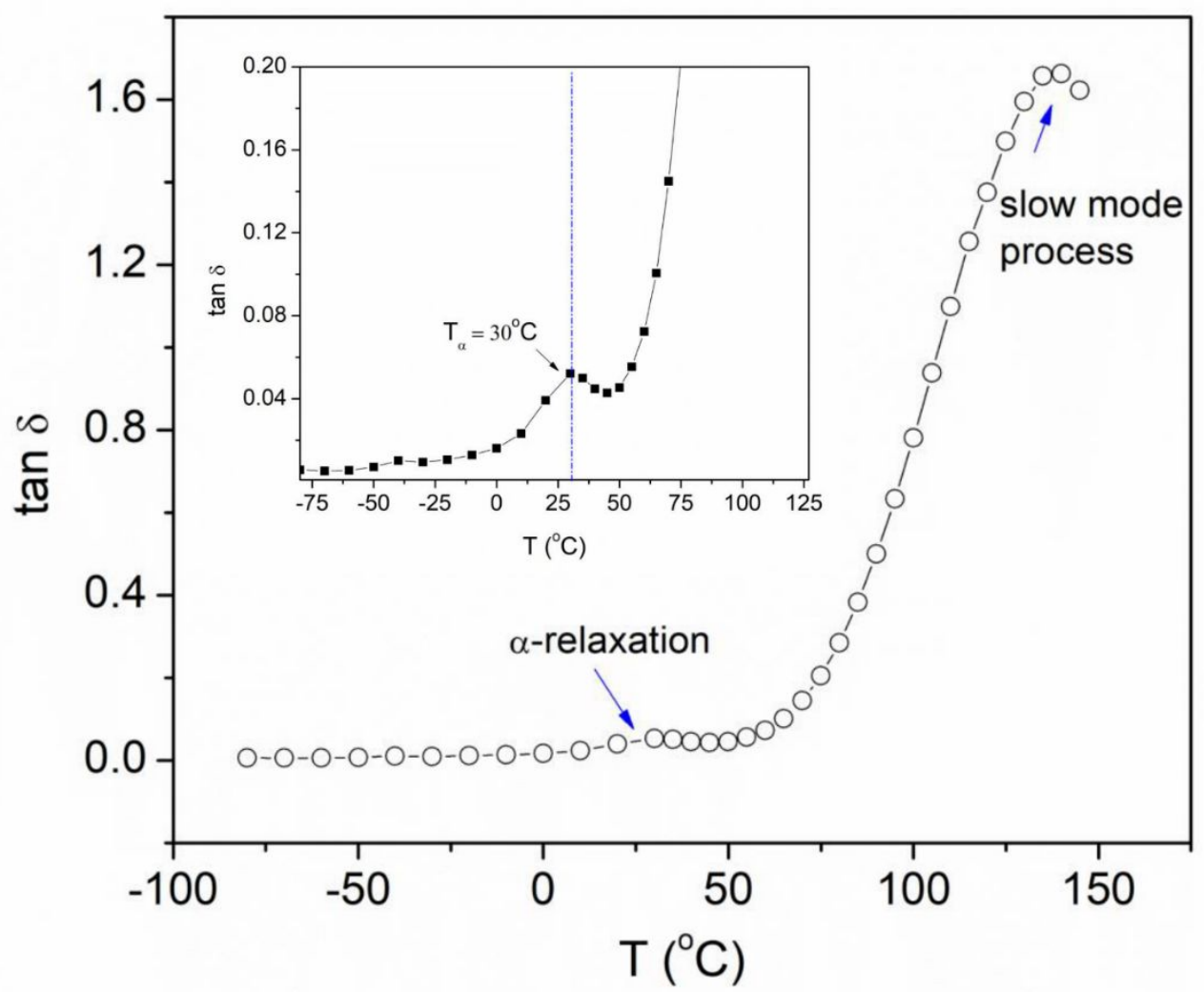

Figure 11. The plot of $\tan \delta$ against temperature at $1 \mathrm{kHz}$. The inset focusses on the $\alpha$ relaxation in the temperature ranging from -100 to $150^{\circ} \mathrm{C}$.

Another relaxation process appears at lower frequencies than the structural relaxation and is designated as the slow mode process. However, this relaxation is only visible in a very narrow temperature range and moved out from our measurement frequency window below $75^{\circ} \mathrm{C}$. Similar slow modes were previously detected for other carbohydrates but their origin remains unclear [62, 63]. Kaminski et al., for example, attributed this process to the long-range correlation of density fluctuation (LRCDF), i.e., from the diffusion of clusters [62]. However, LRCDF can be usually detected in a limited range of temperature around $\mathrm{T}_{\mathrm{g}}+100 \mathrm{~K}$ [63], and the dielectric strength of the cluster relaxation decreases rapidly at higher temperatures, particularly at the liquid state. The 
fact that this relaxation is observed in $\alpha \mathrm{ManPKO}$ at higher temperatures, $140^{\circ} \mathrm{C}$, questions this assignation.

In order to further understand the nature of the previous processes, the experimental complex dielectric permittivity, $\varepsilon^{*}(\omega)$, was fit to a sum of Havriliak-Negami functions in the frequency domain [64]:

$$
\varepsilon^{*}(\omega)=i \omega \sum_{k} \frac{\Delta \varepsilon_{k}}{\left(\left(1+\left(i \omega \tau_{k}\right)^{\beta}\right)^{\delta}\right.}+\varepsilon_{\infty}+i \frac{\sigma_{d c}}{\omega^{\gamma}}
$$

where, $\Delta \varepsilon, \tau$ and $\varepsilon_{\infty}$ are the dielectric strength, relaxation time and instantaneous permittivity, respectively, and $\beta, \delta$ and $\gamma$ are shape parameters describing the distribution of relaxation time. The subscript $k$ represents one individual dielectric relaxation processes. We found a very good agreement between observed and fitted spectra. The $\Delta \varepsilon$ and $\tau$ values of both processes are presented in Figure 12. We can observe how the dielectric strength of the slow mode decreases significantly with decreasing temperature, while for the structural relaxation the reduction on cooling is comparatively slower. Again, the dielectric strength of the slow mode did not follow the LRCDF trend, where the $\Delta \varepsilon$ supposed to increase with increasing temperature. Thus, this slow mode may not be identified as the cluster relaxation. 

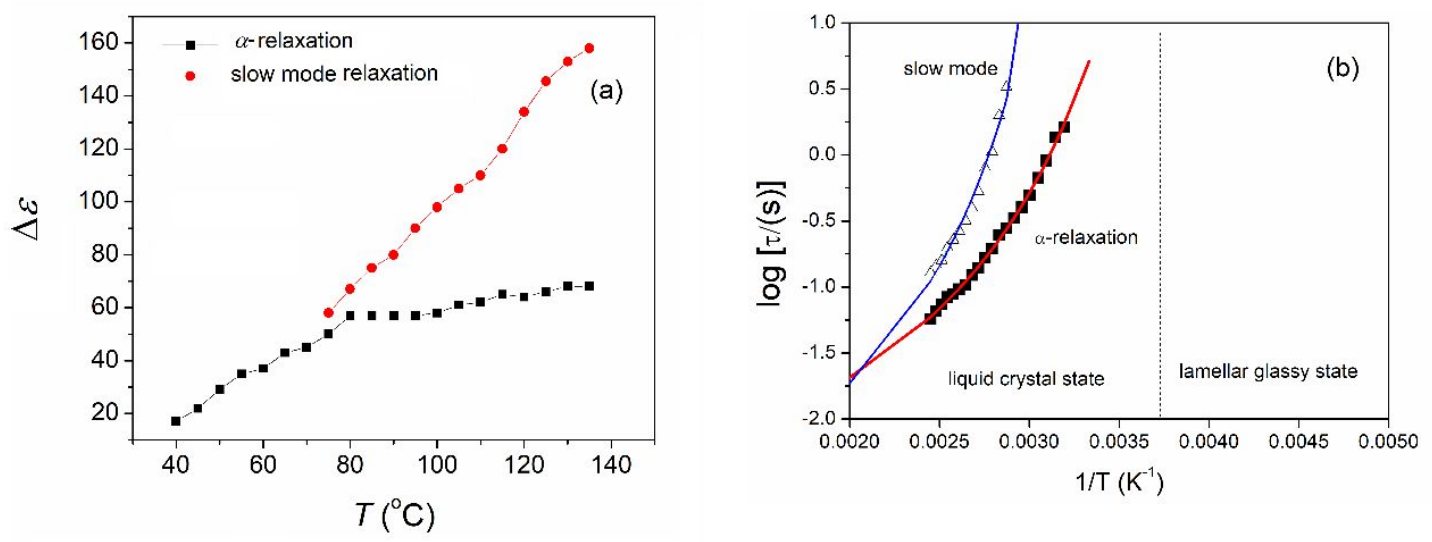

Figure 12. Temperature dependence of (a) dielectric strength and (b) relaxation time, corresponding the structural and slow mode relaxations of $\alpha \mathrm{ManPKO}$.

On the other hand, the $\alpha$-relaxation, which is associated to the glass transition, has a non-Arrhenius temperature dependence that can be describe by the Vogel-Fulcher-Tamman (VFT) equation [65]:

$$
\tau_{\alpha}=\tau_{V F T} \exp \left(\frac{D_{T} T_{O}}{T-T_{O}}\right), \quad\left(T_{\mathrm{o}}<T\right)
$$

where $T_{o}$ is the Vogel or ideal glass transition temperature. The activation energy increases on cooling, following a super-Arrhenius temperature dependence, and the relaxation time becomes infinite at $T_{0}$. The $\tau_{\mathrm{VFT}}$ is the relaxation time at the high temperature limit, which usually falls within the $10^{-14}$ to $10^{-13}$ range of typical molecular vibration times, while $D_{\mathrm{T}}$ is the fragility index or parameter which determines the deviation from Arrhenius behaviour [66]. Figure 12(b) shows the relaxation map of the structural and slow-mode relaxations that we observed for $\alpha$ ManPKO. Both relaxations were fitted to VFT behaviour (equation 3) and the parameters are displayed in Table 3. The glass transition, $T_{g}$, and the freezing, $T_{f}$, temperatures were estimated for the 
structural and slow mode relaxations, respectively. Both $\mathrm{T}_{\mathrm{f}}$ and $\mathrm{T}_{\mathrm{g}}$ are defined as temperature at which relaxation time of slow and structural modes are equal to $\tau=100 \mathrm{~s}$, respectively. However, the $\mathrm{T}_{\mathrm{f}}$ nomenclature was used for slow mode to distinguish the $\mathrm{T}_{\mathrm{g}}$ for which is generally linked to the structural relaxation. $\mathrm{T}_{\mathrm{f}}$ is much higher than $\mathrm{T}_{\mathrm{g}}$ and such behaviour is reasonable because the structural relaxation involves cooperatively rearranging regions of about $\sim 4 \AA$ (see Table 3 ) while for the slow mode relaxation these are estimated around $40 \AA$ (will be further discussed later).

Table 3. Summary of parameters for the structural and slow mode relaxation for the $\alpha$ ManPKO.

\begin{tabular}{lccccc}
\hline & \multicolumn{1}{l}{$\mathrm{T}_{o}\left[\tau_{\mathrm{VFT}} / \mathrm{s}\right]$} & & $D_{\mathrm{T}}$ & $\mathrm{T}$ & $\lambda$ \\
& $(\mathrm{K})$ & & $(\mathrm{K})$ & $(\AA)$ \\
\hline Structural & -7.40 & 139 & 21 & $\mathrm{~T}_{g}$ & $4.01 \pm$ \\
relaxation & & & & 274 & 0.05 \\
Slow mode & -1.81 & 309 & 0.68 & $\mathrm{~T}_{f}$ & \\
relaxation & & & & 309 & \\
\hline
\end{tabular}

The microscopic features of the ionic motion can be then modelled by the random walk scheme with step length $\lambda$ and step time $\tau_{\mathrm{o}}$. The diffusion coefficient, $D$ is obtained using the EinsteinSmoluchowski equation:

$$
D=\frac{\lambda^{2}}{6 \tau_{o}}
$$

For a system containing $N$ molecules of $\alpha$ ManPKO with charge $q$, the dc conductivity, $\sigma_{d c}$ and the diffusion coefficient, $D$ are related by:

$$
\sigma_{d c}=\frac{N q^{2}}{k T} D
$$


where $k$ is the Boltzmann constant and $T$ is the absolute temperature. Considering that $\tau_{\mathrm{o}}=1 / 2 \pi f_{m}$ , where $f_{\mathrm{m}}$ is the relaxation frequency of the process, we have measured the hopping length, $\lambda$, of the charge carriers from bilayers and confined regions in the previous relaxations, by using equations (4) and (5) [67, 68]. The results are displayed in Table 3. The $\alpha$-relaxation process has a hopping length of $\lambda \sim 4 \AA$, in the range of the intermolecular hydrogen bond distances. This relaxation involves segmental motions of the glycoside molecules, which clearly depend on their intermolecular interactions. Our results pinpoint the role of hydrogen bonding between the lipids head groups in $\alpha \mathrm{ManPKO}$ on the activation of the segmental motions, which we ascribed to strong hydrogen bonds by FT-IR. More specifically, the rotation of the sugar groups must onset the motion of free charge carriers to hop between different molecules, see Figure 13.

On the other hand, the slow mode process involves a longer hopping length of $\lambda \sim 39 \AA$, closer to the bilayer length that we obtained by SWAXS. Charge carriers can be trapped at the bilayers, and thermal motions allow the carriers to overcome the energy barrier and start diffusing, but at a much slower rate $\left(D_{\mathrm{T}}=0.68\right.$ is over thirty times smaller than for the $\alpha$-relaxation, see Table 3$)$. We believe that the process is associated to disruptions of the smectic phase by translational movements of the sugar head groups, activated at high temperatures and low frequencies, Figure 13. If we assume that the so-called weak hydrogen bonds are responsible of the smectic phase stability, see our FT-IR results, the clearance of some of these may facilitate movements of the aManPKO molecules around their long axis, which ultimately leads to the destruction of mesomorphic order. A comparable molecular phenomenon is observed in methacrylate-based side-chain liquid crystal copolymers, SCLCP, known as $\delta$ relaxation $[69,70,71,72]$, and ascribed to rotations of the side-chains groups around the polymer backbone. The increase of free volume 
around the polymer backbone by flip-flop motions of the ester groups near the main chain in the SCLCP, ultimately allows for the long-range mobility of the side groups. This effect may be equivalent to a weakening of the hydrogen bonds between glycosides, which activates the slow mode relaxation, and ultimately disrupts the smectic structure in $\alpha$ ManPKO.

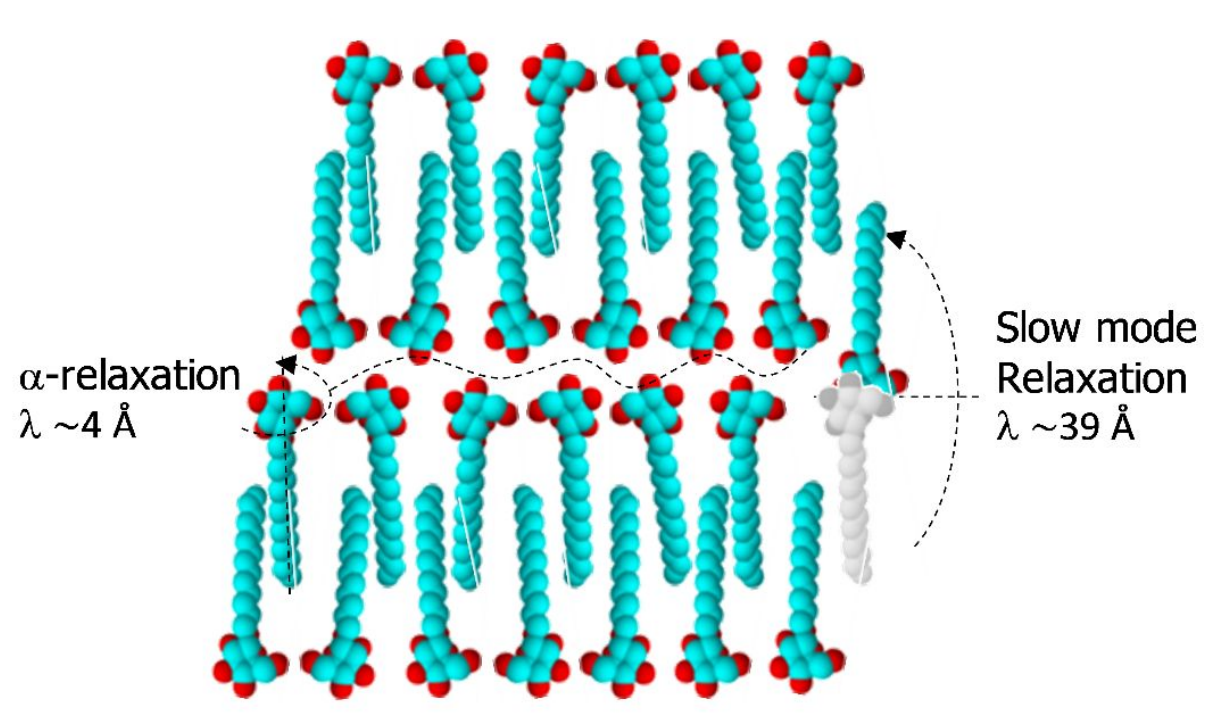

Figure 13. Schematic representation of the dielectric relaxation modes found for $\alpha \mathrm{ManPKO}$.

\section{Conclusions}

The new glycoside synthesised, $\alpha$ ManPKO, exhibits monotropic smectic A behaviour on cooling in a broad temperature range, and vitrifies below room temperature. $\alpha \mathrm{ManPKO}$ forms bilayers with some degree of interdigitation between alkyl chains of different layers, and the stability of the microphase separated structure is controlled by a combination of weak hydrogen bonds between the mannose heads and long-range motions above certain temperature. The smectic layer distance of $\alpha \mathrm{ManPKO}$ is mainly determined by the major unsaturated component, $\alpha \mathrm{ManC}_{18: 1}$, 
whilst the clearance of strong hydrogen bonds seems to onset short-range motions associated with the glass transition of $\alpha$ ManPKO. Interestingly, however, our results also suggest that the unsaturated character of the alkyl chains of $\alpha \mathrm{ManC}_{18: 1}$ may have a stronger effect on vitrification of $\alpha$ ManPKO than some previous findings in other glycosides [21, 37]. Octyl-maltosides, for example, show glass transitions that are absent in the glucoside analogues [37], and dodecylglucosides vitrify and show cold crystallisation effects before melting to smectic ranges [21, 73]. All these results highlight the potential of natural-based, non-ionic and non-polymeric, glycosides, based on their thermotropic liquid crystal properties, and the possibility to control their microstructure via molecular design and the stability of the intermolecular interactions.

\section{Acknowledgement}

This work was supported by the Ministry of Education of Malaysia [600-RMI/RAGS 5/3 (140/2014), 2014]; University Malaya [RP038B-17AFR, 2017]; Royal Academy of Engineering, U.K., and Academy of Science, Malaysia [NRCP1516/4/61, 2016] and the University of Aberdeen [SF10192, 2018]. AMF and TS would like to acknowledge the financial support provided by University Malaya for the Visiting Lecturer fellowship. 


\section{References}

1. Goodby JW, Pfannemüller B, Welte W, et al. Liquid-crystalline glycolipids: towards understanding the roles of liquid crystals in biological and life processes. Liq Cryst. 2006;33(11-12):1229-1245.

2. Hashim R, Sugimura A, Minamikawa $H$, et al. Nature-like synthetic alkyl branched-chain glycolipids: a review on chemical structure and self-assembly properties. Liq Cryst. 2011;39(1):1-17.

3. Konidala $\mathrm{P}, \mathrm{He} \mathrm{L}$, Niemeyer B. Molecular dynamics characterization of n-octyl- $\beta$ - $d$ glucopyranoside micelle structure in aqueous solution. J Mol Graph Model. 2006;25(1):77-86.

4. Hannun YA, Bell RM. Functions of sphingolipids and sphingolipid breakdown products in cellular regulation. Science. 1989;243(4890):500-507.

5. Fendler JH. Membrane mimetic chemistry: characterizations and applications of micelles, microemulsions, monolayers, bilayers, vesicles, host-guest systems, and polyions. New York: Wiley; 1982.

6. Lasic DD. Liposomes: from physics to applications. Amsterdam: Elsevier; 1993.

7. von Rybinski W, Hill K. Alkyl polyglycosides-properties and applications of a new class of surfactants. Angew Chem Int Ed. 1998;37(10):1328-1345.

8. Aripin NFK, Park JW, Park HJ. Preparation of vesicle drug carrier from palm oil- and palm kernel oil-based glycosides. Colloids Surf B. 2012;95(Supplement C):144-153.

9. Aripin NFK, Hashim R, Heidelberg $T$, et al. Effect of vesicle's membrane packing behaviour on skin penetration of model lipophilic drug. J Microencapsul. 2013;30(3):265-273.

10. Teo BSX, Basri M, Zakaria MRS, et al. A potential tocopherol acetate loaded palm oil esters-in-water nanoemulsions for nanocosmeceuticals. J Nanobiotechnology. 2010;8(1):4.

11. Musa SH, Basri M, Masoumi HRF, et al. Formulation optimization of palm kernel oil esters nanoemulsion-loaded with chloramphenicol suitable for meningitis treatment. Colloids Surf B. 2013;112:113-119.

12. Pantzaris T, Basiron Y. The lauric (coconut and palm kernel) oils. In: Gunstone FD, editor. Vegetable Oils in Food Technology: Composition, Properties, and Uses: Blackwell; 2002. p. 157.

13. Loo $\mathrm{CH}$, Basri M, Ismail R, et al. Effect of compositions in nanostructured lipid carriers (NLC) on skin hydration and occlusion. Int J Nanomedicine. 2013;8:13-22.

14. Hung LC, Basri M, Tejo BA, et al. An improved method for the preparations of nanostructured lipid carriers containing heat-sensitive bioactives. Colloids Surf B. 2011;87(1):180-186.

15. Puglia C, Bonina F. Lipid nanoparticles as novel delivery systems for cosmetics and dermal pharmaceuticals. Expert Opin Drug Deliv. 2012;9(4):429-441.

16. Vill V, Böcker T, Thiem J, et al. Studies on liquid-crystalline glycosides. Liq Cryst. 1989;6(3):349-356. 
17. Vill V, von Minden HM, Koch $\mathrm{MH}$, et al. Thermotropic and lyotropic properties of long chain alkyl glycopyranosides. Part I: monosaccharide headgroups. Chem Phys Lipids. 2000;104(1):75-91.

18. von Minden HM, Brandenburg K, Seydel U, et al. Thermotropic and lyotropic properties of long chain alkyl glycopyranosides. Part II. Disaccharide headgroups. Chem Phys Lipids. 2000;106(2):157-79.

19. Boyd BJ, Drummond CJ, Krodkiewska I, et al. How Chain Length, Headgroup Polymerization, and Anomeric Configuration Govern the Thermotropic and Lyotropic Liquid Crystalline Phase Behavior and the Air-Water Interfacial Adsorption of GlucoseBased Surfactants. Langmuir. 2000;16(19):7359-7367.

20. Goodby JW. Liquid Crystal Phases Exhibited by Some Monosaccharides. Mol Cryst Liq Cryst. 1984;110(1-4):205-219.

21. Ogawa $\mathrm{S}$, Asakura K, Osanai $\mathrm{S}$. Thermotropic and glass transition behaviors of $n$-alkyl $\beta$ d-glucosides. RSC Adv. 2013;3(44).

22. Hori R, Ikegami Y. Studies on Carbohydrate Derivatives. V Syntheses of Alkyl Galactosides and Alkyl Glucosides. Yakugaku Zasshi. 1959;79(1):80-83.

23. Chen G, Li Z, Chen L, et al. Synthesis and properties of Alkyl $\alpha$-D-Galactopyranoside. J Dispers Sci Technol. 2016;38(4):506-514.

24. Chen G, Li Z, Chen L, et al. Synthesis and Properties of Alkyl $\beta$-d-Galactopyranoside. J Surfactants Deterg. 2016;19(6):1095-1105.

25. Koeltzow DE, Urefer AD. Preparation and properties of pure alkyl glucosides, maltosides and maltotriosides. J Am Oil Chem Soc. 1984;61(10):1651-1655.

26. Hu X, Shi Y, Zhang P, et al. d-Mannose: Properties, Production, and Applications: An Overview. Compr Rev Food Sci Food Saf. 2016;15(4):773-785.

27. Toyota S, Fukushi Y, Katoh S, et al. Anti-bacterial defense mechanism of the urinary bladder, role of mannose in urine. The Japanese Journal of Urology. 1989;80(12):18161823.

28. Tonnesen AS. Clinical Pharmacology and Use of Diuretics. ASA Refresher Courses in Anesthesiology. 1983;11:217-236.

29. Nystrom RF, Brown WG. Reduction of Organic Compounds by Lithium Aluminum Hydride. I. Aldehydes, Ketones, Esters, Acid Chlorides and Acid Anhydrides. J Am Chem Soc. 1947;69(5):1197-1199.

30. Oborn RE, Ullman AH. A capillary gas chromatographic method for the characterization of linear fatty alcohols. J Am Oil Chem Soc. 1986;63(1):95-97.

31. Hashim R, Hashim HHA, Rodzi NZM, et al. Branched chain glycosides: Enhanced diversity for phase behavior of easily accessible synthetic glycolipids. Thin Solid Films.

2006;509(1-2):27-35.

32. Patrick M, Zahid NI, Kriechbaum M, et al. Guerbet glycolipids from mannose: liquid crystals properties. Liq Cryst. 2018:1-17.

33. Gorin PAJ, Perlin AS. Configuration of Glycosidic Linkages in Oligosaccharides: IX. Synthesis of $\alpha$ - and $\beta$-D-Mannapyranosyl Disaccharides. Can J Chem 1961;39(12):24742485.

34. Zhang Y, Chen L, Wu X. Thermotropic liquid crystalline and surface-active properties of n-alkyl a-d-mannopyranosides. J Mol Liq. 2018. 
35. Stubbs CD, Smith AD. The modification of mammalian membrane polyunsaturated fatty acid composition in relation to membrane fluidity and function. Biochim Biophys Acta. 1984;779(1):89-137.

36. Ericsson CA, Ericsson LC, Kocherbitov V, et al. Thermotropic phase behaviour of longchain alkylmaltosides. Phys Chem Chem Phys. 2005;7(15):2970-7.

37. Kocherbitov V, Soderman O. Glassy crystalline state and water sorption of alkyl maltosides. Langmuir. 2004;20(8):3056-61.

38. Kamal-Eldin A. Effect of fatty acids and tocopherols on the oxidative stability of vegetable oils. Eur J Lipid Sci Technol. 2006;108(12):1051-1061.

39. Cosgrove JP, Church DF, Pryor WA. The kinetics of the autoxidation of polyunsaturated fatty acids. Lipids. 1987;22(5):299-304.

40. Brown G, Dubreuil P, Ichhaporia F, et al. Synthesis and properties of some $\alpha$-d-alkyl glucosides and mannosides: apparent molal volumes and solubilization of nitrobenzene in water at 25 C. Can J Chem. 1970;48(16):2525-2531.

41. Sakya P, Seddon JM. Thermotropic and lyotropic phase behaviour of monoalkyl glycosides. Liq Cryst. 1997;23(3):409-424.

42. Cook AG, Martinez-Felipe A, Brooks NJ, et al. New insights into the transitional behaviour of methyl-6-O-(n-dodecanoyl)- $\alpha$-D-glucopyranoside using variable temperature FTIR spectroscopy and X-ray diffraction. Liq Cryst. 2013;40(12):1817-1827.

43. Cook AG, Wardell JL, Imrie CT. Carbohydrate liquid crystals: synthesis and characterisation of the methyl-6-O-(n-acyl)-alpha-D-glucopyranosides. Chem Phys Lipids. 2011;164(2):118-24.

44. Size of glucose ring molecule Apr 8, 2014 [cited 20184 February]. Available from: http://bionumbers.hms.harvard.edu//bionumber.aspx?id=110368\&ver $=0$

45. Martínez-Felipe A, Cook AG, Wallage MJ, et al. Hydrogen bonding and liquid crystallinity of low molar mass and polymeric mesogens containing benzoic acids: a variable temperature Fourier transform infrared spectroscopic study. Phase Transit. 2014;87(12):1191-1210.

46. Abdy MJ, Murdoch A, Martínez-Felipe A. New insights into the role of hydrogen bonding on the liquid crystal behaviour of 4-alkoxybenzoic acids: a detailed IR spectroscopy study. Liq Cryst. 2016;43(13-15):2191-2207.

47. Martinez-Felipe A, Brebner F, Zaton D, et al. Molecular recognition via hydrogen bonding in supramolecular complexes: A fourier transform infrared spectroscopy study. Molecules. 2018;23(9):2278.

48. Martínez-Felipe A, Imrie CT, Ribes-Greus A. Study of structure formation in side-chain liquid crystal copolymers by variable temperature Fourier transform infrared spectroscopy. Ind Eng Chem Res. 2013;52(26):8714-8721.

49. Wolkers WF, Oliver AE, Tablin F, et al. A Fourier-transform infrared spectroscopy study of sugar glasses. Carbohydr Res. 2004;339(6):1077-85.

50. Cook AG, Inkster RT, Martinez-Felipe A, et al. Synthesis and phase behaviour of a homologous series of polymethacrylate-based side-chain liquid crystal polymers. Eur Polym J. 2012;48(4):821-829.

51. Angell CA. Formation of glasses from liquids and biopolymers. Science. 1995;267(5206):1924-1935. 
52. Mano JF. Cooperative character of the relaxation processes in a side-chain liquid crystalline polymer. J Macromol Sci B 2003;42(6):1169-1182.

53. Angell CA, Imrie CT, Ingram MD. From simple electrolyte solutions through polymer electrolytes to superionic rubbers: some fundamental considerations. Polym Int. 1998;47(1):9-15.

54. Jeffrey G. Molecular Packing and Hydrogen Bonding in the Crystal Structures of the N-(nAlkyl)-D-gluconamide and the 1-Deoxy-(N-methyl-alkanamido)-D-glucitol Mesogens. Mol Cryst Liq Cryst. 1990;185(1):209-213.

55. Jeffrey GA. Carbohydrate liquid crystals. Acc Chem Res. 1986;19(6):168-173.

56. van Doren H, Buma T, Kellogg RM, et al. Carbohydrate liquid crystals even at ambient temperature. J Chem Soc Chem Commun. 1988(7):460-462.

57. Van Doren H, Wingert L. A revised model for the molecular arrangement in the smectic Ad phase of carbohydrate derived amphiphiles with one alkyl chain. Mol Cryst Liq Cryst. 1991;198(1):381-391.

58. Chong TT, Heidelberg T, Hashim R, et al. Computer modelling and simulation of thermotropic and lyotropic alkyl glycoside bilayers. Liq Cryst. 2007;34(2):267-281.

59. Biegler-König F, Schönbohm J. Update of the AIM2000-Program for atoms in molecules. J Comput Chem. 2002;23(15):1489-1494.

60. Sakya P, Seddon J. Thermotropic and lyotropic phase behaviour of monoalkyl glycosides. Liq Cryst. 1997;23(3):409-424.

61. Noel TR, Parker R, Ring SG. Effect of molecular structure and water content on the dielectric relaxation behaviour of amorphous low molecular weight carbohydrates above and below their glass transition. Carbohydr Res. 2000;329(4):839-845.

62. Kaminski K, Kaminska E, Adrjanowicz K, et al. Observation of the dynamics of clusters in D-glucose with the use of dielectric spectroscopy. Phys Chem Chem Phys. 2010;12(3):723-30.

63. Kaminski K, Wlodarczyk P, Adrjanowicz K, et al. Origin of the Commonly Observed Secondary Relaxation Process in Saccharides. J Phys Chem B. 2010;114(34):1127211281.

64. Havriliak S, Negami S. A complex plane representation of dielectric and mechanical relaxation processes in some polymers. Polymer. 1967;8:161-210.

65. Vogel H. The temperature dependence law of the viscosity of fluids. 1921;22:645-646.

66. Angell CA. Relaxation in liquids, polymers and plastic crystals - strong/fragile patterns and problems. J Non-Cryst Solids. 1991;131-133:13-31.

67. Furukawa T, Mukasa Y, Suzuki T, et al. Microphase separation and ion-conduction mechanisms in polypropylene oxide/lithium perchlorate (LiClO4) complexes. J Polym Sci B. 2002;40(7):613-622.

68. Velayutham TS, Ng BK, Gan WC, et al. Phase sensitive molecular dynamics of selfassembly glycolipid thin films: a dielectric spectroscopy investigation. J Chem Phys. 2014;141(8):085101.

69. Mano JF, Gómez Ribelles JL. Mechanical Spectroscopy Studies on a Side-Chain Liquid Crystalline Polysiloxane. Comparison with Dielectric and DSC Data. Macromolecules. 2003;36(8):2816-2824. 
70. Zentel R, Strobl GR, Ringsdorf H. Dielectric relaxation of liquid crystalline polyacrylates and polymethacrylates. Macromolecules. 1985;18(5):960-965.

71. Romero Colomer F, Meseguer Duenas JM, Gomez Ribelles JL, et al. Side-chain liquid crystalline poly(N-maleimides). 5. Dielectric relaxation behavior of liquid crystalline sidechain and amorphous poly(N-maleimides). A comparative structural study. Macromolecules. 1993;26(1):155-166.

72. Vanti L, Mohd Alauddin S, Zaton D, et al. Ionically conducting and photoresponsive liquid crystalline terpolymers: Towards multifunctional polymer electrolytes. Eur Polym J. 2018;109:124-132.

73. Ericsson CA, Ericsson LC, Ulvenlund S. Solid-state phase behaviour of dodecylglycosides. Carbohydr Res. 2005;340(8):1529-37. 
Figure 1. Chemical structures of major components in aManPKO. The mannosides studied in the present work are aManPKO, aManC 12 and $\mathrm{aManC}_{18: 1}$ (bold text). 


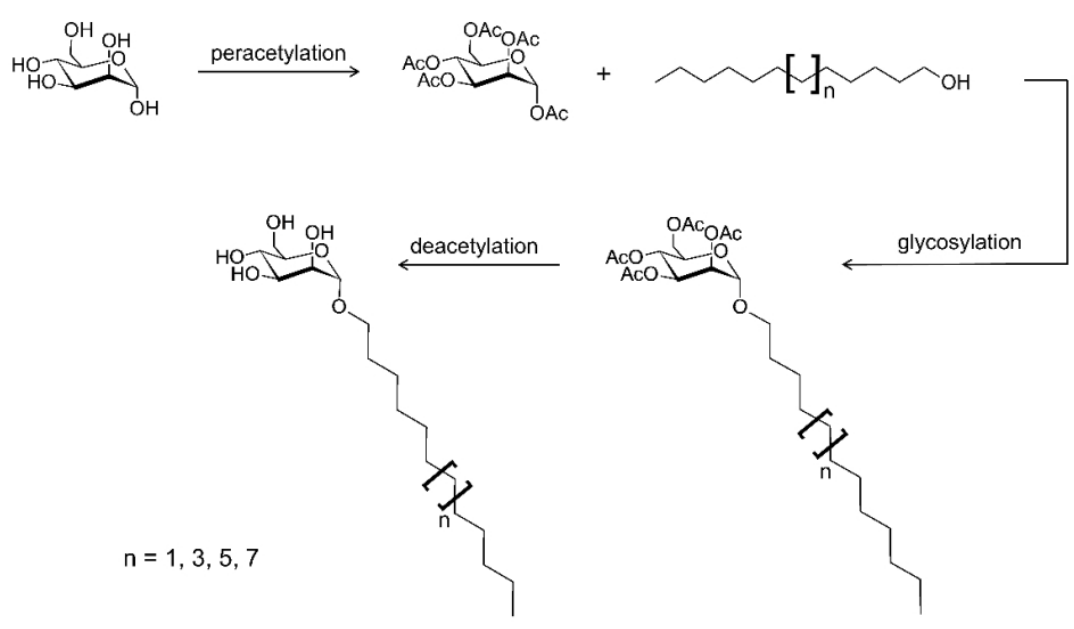

Figure 2. Synthesis route overview $160 \times 90 \mathrm{~mm}(220 \times 220$ DPI $)$ 
Figure 3. DSC traces of (a) aManC $18: 1$, (b) aManPKO, and (c) aManC 12 corresponding to the second heating scan. The inset highlights the $T_{g}$ of the mannosides. In these graphs, curves have been rescaled and shifted along the $y$-axis. The dotted arrow corresponds to the clearing temperature $\left(T_{C}=146^{\circ} \mathrm{C}\right)$ for aManPKO. 


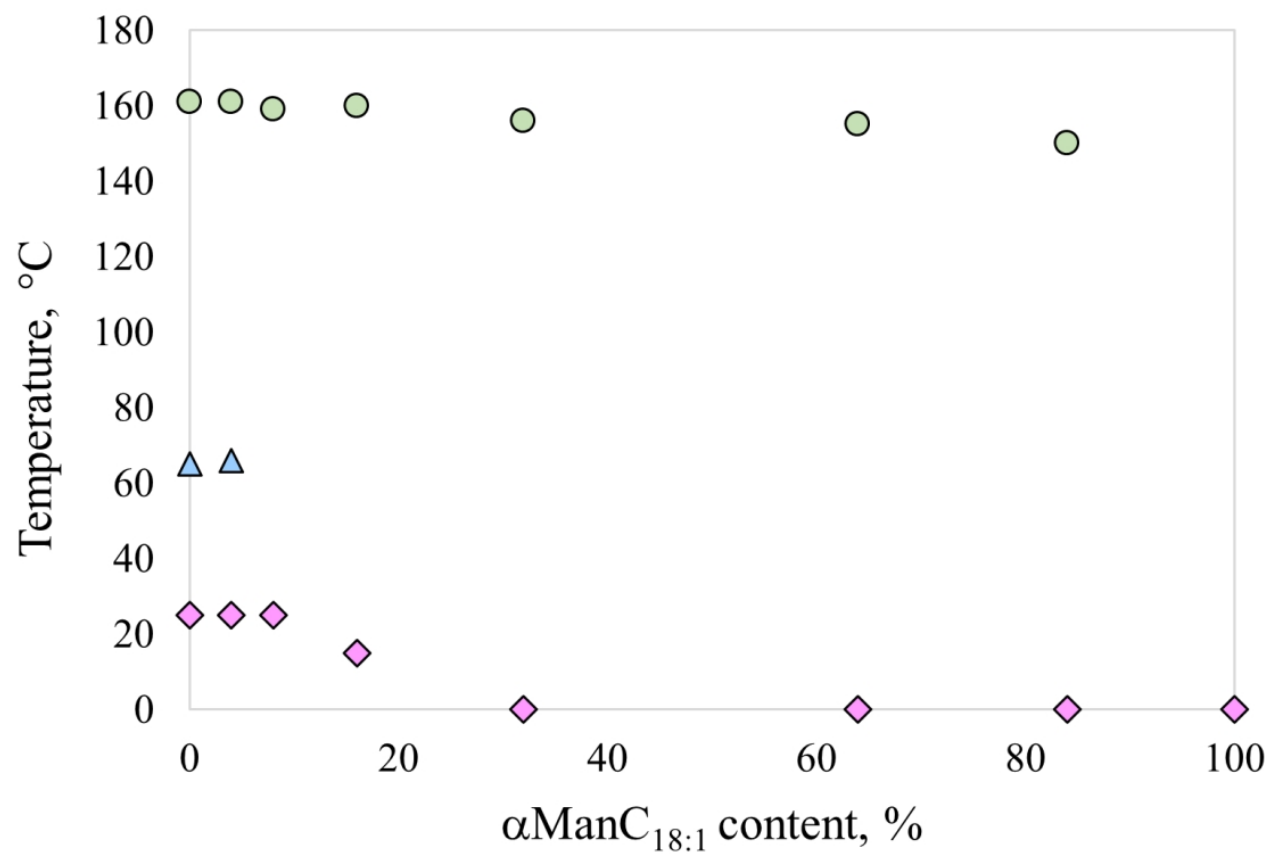

Figure 4. Phase diagram constructed for binary mixtures of aManC12 and aManC18:1. The diamonds represent $T_{g}$, triangles represent $T_{m}$ and circles, $T_{c}$. 
(a)

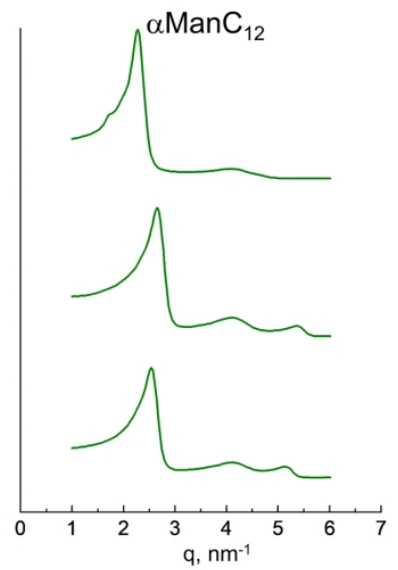

(b)

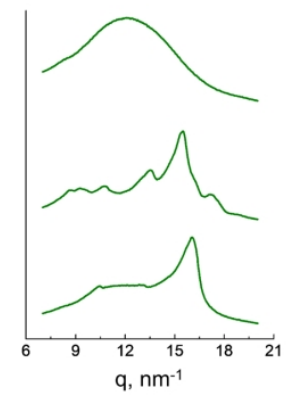

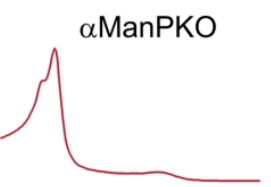
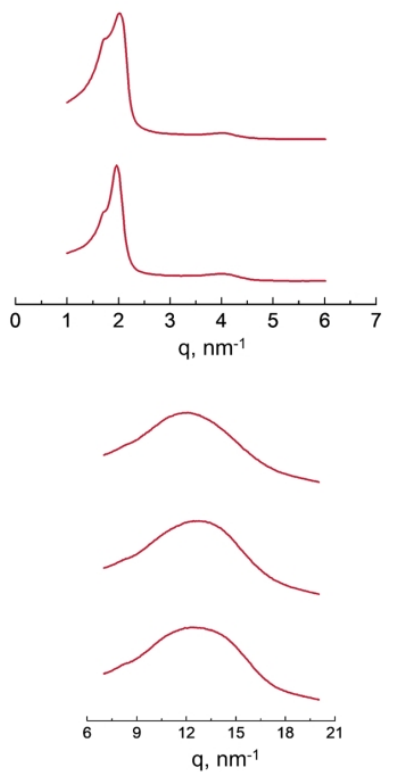
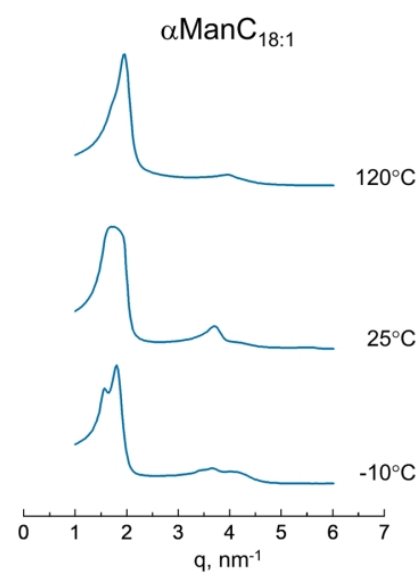

$-10^{\circ} \mathrm{C}$

Figure 5. Small/wide angle x-ray scattering patterns, SWAXS, obtained for aManPKO, aManC 12 and aManC $18: 1$ on heating, $T=-10,25$, and $120^{\circ} \mathrm{C}$. The small angle $\mathrm{x}$-ray scatterings are shown in (a) while the wide-angle regions are shown in (b). Curves are arbitrarily shifted along the $y$-axis. 


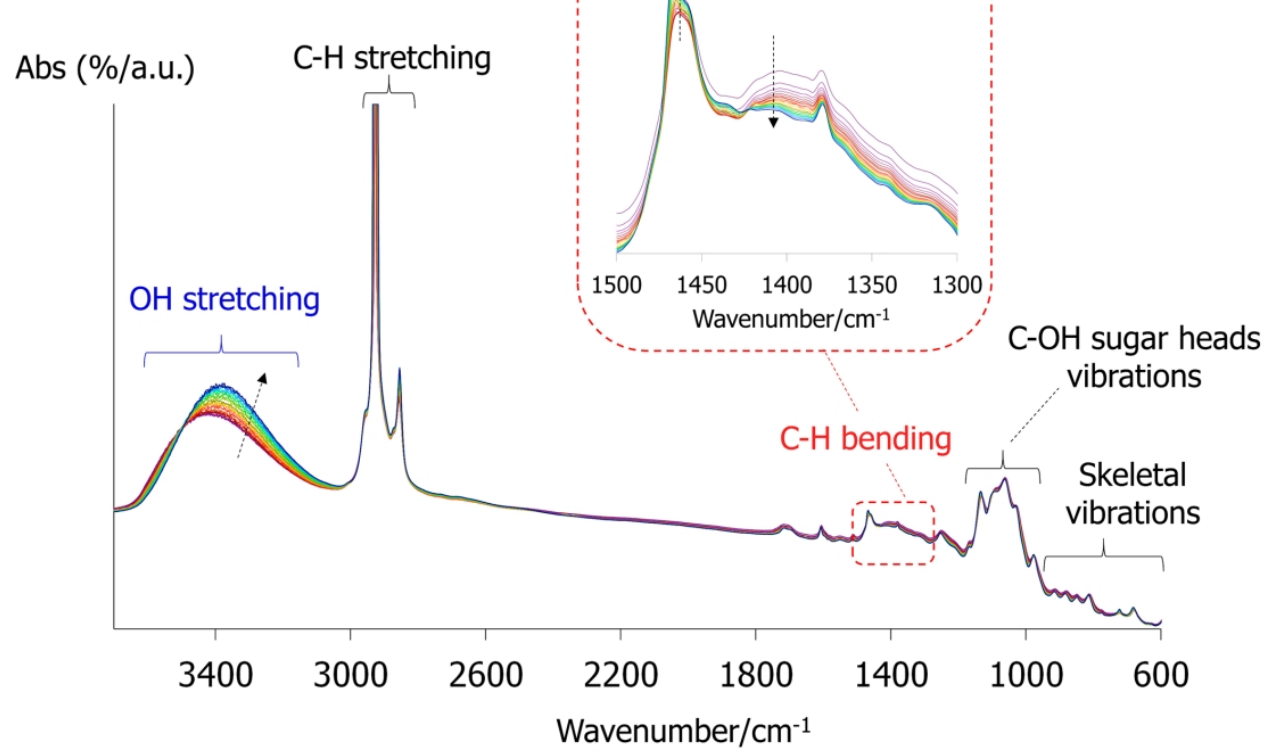

Figure 6. Temperature dependence of the FT-IR spectra of aManPKO, highlighting the O-H stretching, st., and $\mathrm{C}-\mathrm{H}$ bending, $\delta$. regions. Arrows indicate direction on cooling. 


\section{Max wavenumber/cm-1}

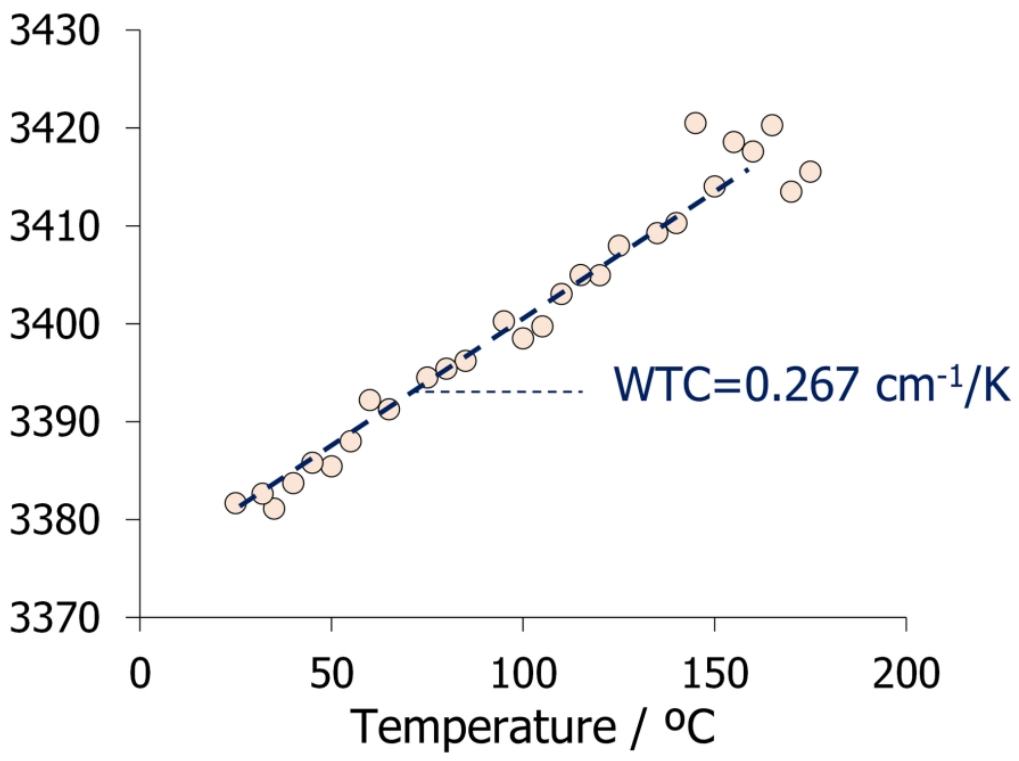

Figure 7. Temperature dependence of the $\mathrm{O}-\mathrm{H}$ stretching band maximum, $\mathrm{v}_{\mathrm{OH}-\mathrm{max}}$ obtained on cooling from the isotropic melt, showing the calculation of the wavenumber-temperature coefficient, WTC.

$$
98 \times 76 \mathrm{~mm}(600 \times 600 \text { DPI })
$$




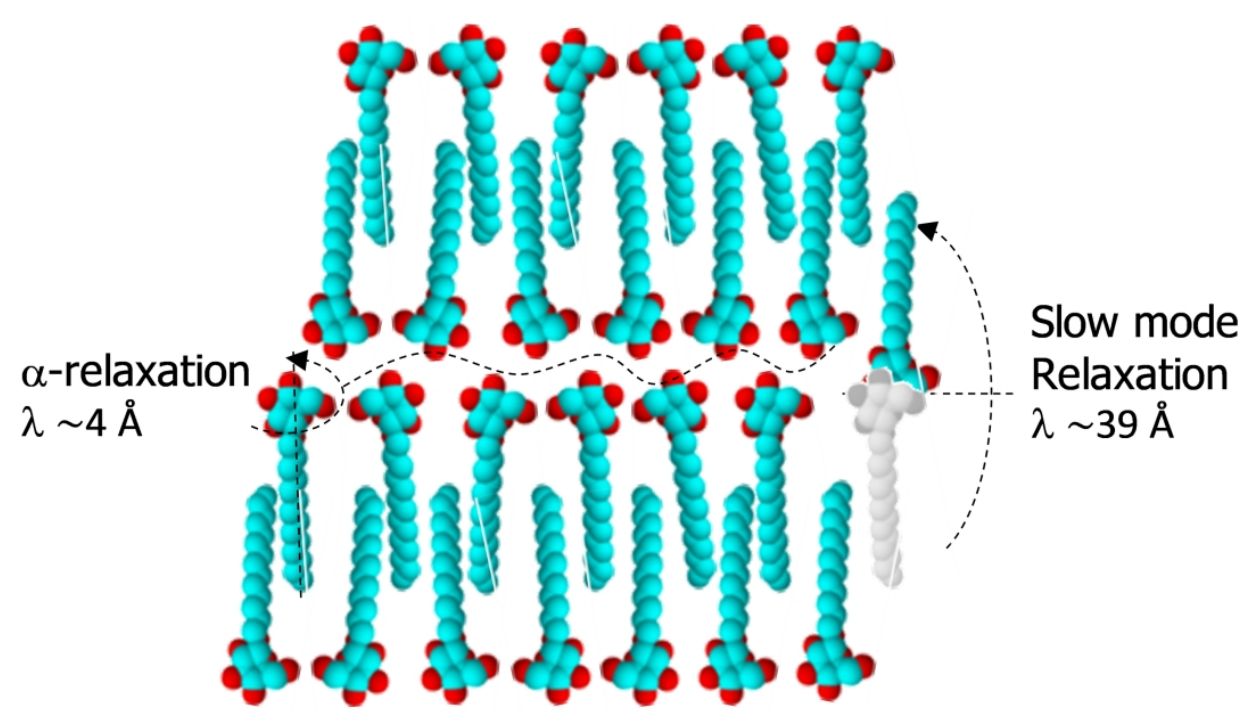

Figure 13. Schematic representation of the dielectric relaxation modes found for aManPKO.

$128 \times 71 \mathrm{~mm}(600 \times 600 \mathrm{DPI})$ 


\section{Glycolipids from Natural Sources: Dry Liquid Crystal Properties, Hydrogen Bonding and Molecular Mobility of Palm Kernel Oil Mannosides}

\section{Electronic Supplementary Information, ESI.}

Alfonso Martinez-Felipe ${ }^{1}$, Thamil Selvi Velayutham²,3, Nurul Fadhilah Kamalul Aripin $^{3,4 *}$, Marina Yusoff 3,4, Emma Farquharson¹, Rauzah Hashim³

${ }^{1}$ Chemical and Materials Engineering Group, School of Engineering, University of Aberdeen. King's College, Aberdeen AB24 3UE, UK.

${ }^{2}$ Low Dimensional Material Research Center, Department of Physics, Faculty of Science, University of Malaya, 50603 Kuala Lumpur, Malaysia.

${ }^{3}$ Fundamental and Frontier Sciences in Nanostructure Self-Assembly Center, Department of Chemistry, Faculty of Science, University of Malaya, 50603 Kuala Lumpur, Malaysia.

${ }^{4}$ Faculty of Chemical Engineering, Universiti Teknologi MARA, 40450 Shah Alam, Malaysia.

*Corresponding author

Email address: fadhilah9413@salam.uitm.edu.my

Phone number: $+603-55438415$ 


\section{Contents}

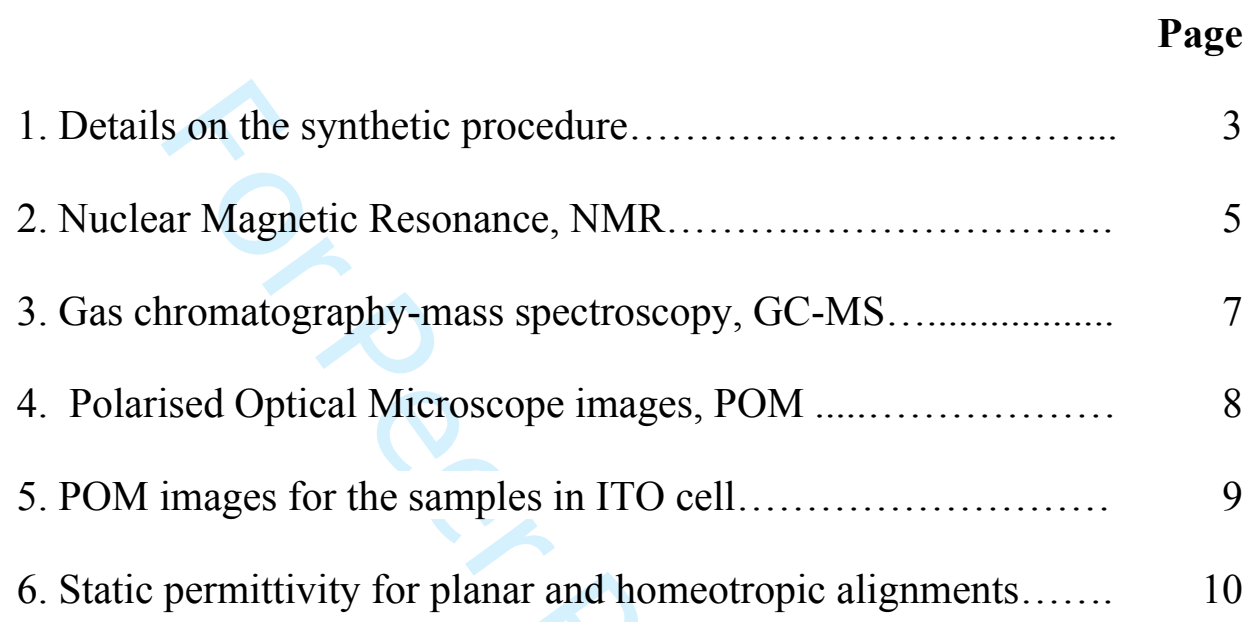




\section{Details on the synthetic procedure}

The synthetic procedure to produce the mannosides consists of three steps.

Peracetylation:

$\mathrm{D}(+)$-mannose monohydrate $(111 \mathrm{mmol})$ was stirred with $100 \mathrm{ml}$ of acetic anhydride in a round bottom flask immersed in an ice bath for 15 minutes before a few drops of concentrated sulfuric acid were added. The ice bath was removed after 25 minutes and the solution was stirred for 45 minutes at room temperature. Several ice water - ethyl acetate extractions were performed to recover the mannose pentaacetate, once the reaction was completed. Saturated sodium hydrogen carbonate solution was added to neutralise the organic solution and anhydrous magnesium sulphate was used to remove remaining water from the solution prior to ethyl acetate evaporation. The product was confirmed by ${ }^{1} \mathrm{H}-\mathrm{NMR}$.

\section{Glycosylation:}

$15 \mathrm{mmol}$ of mannose pentaacetate and $20 \mathrm{mmol}$ of alcohol (dodecanol, oleyl alcohol or reduced $\mathrm{PKO}$ ) were dissolved in $60 \mathrm{ml}$ dichloromethane in a round bottom flask. $\mathrm{BF}_{3}$ (18 mmol) was injected into the solution and the solution was stirred for 24 hours. Glycosylation reaction was stopped by adding saturated sodium hydrogen bicarbonate solution. Following the liquid-liquid extractions, the organic layer was collected, and the solvent was then removed by evaporation. The second extraction was performed using hexane and acetonitrile to completely remove the excess alcohol. In the cases of $\alpha \mathrm{ManC}_{12}$ and $\alpha \mathrm{ManC}_{18: 1}$, additional purification using column chromatography was carried out. 


\section{Deacetylation:}

A methanolic solution of acetylated mannoside was stirred for at least 12 hours with a catalytic amount of sodium methoxide. Methanol was evaporated after neutralisation with diluted sulfuric acid. The final product was purified by butanol-water extractions which were then allowed to dry in vacuum at $50^{\circ} \mathrm{C}$ for 48 hours, prior to the ${ }^{1} \mathrm{H}-\mathrm{NMR}$ assessment. 


\section{NMR spectra}

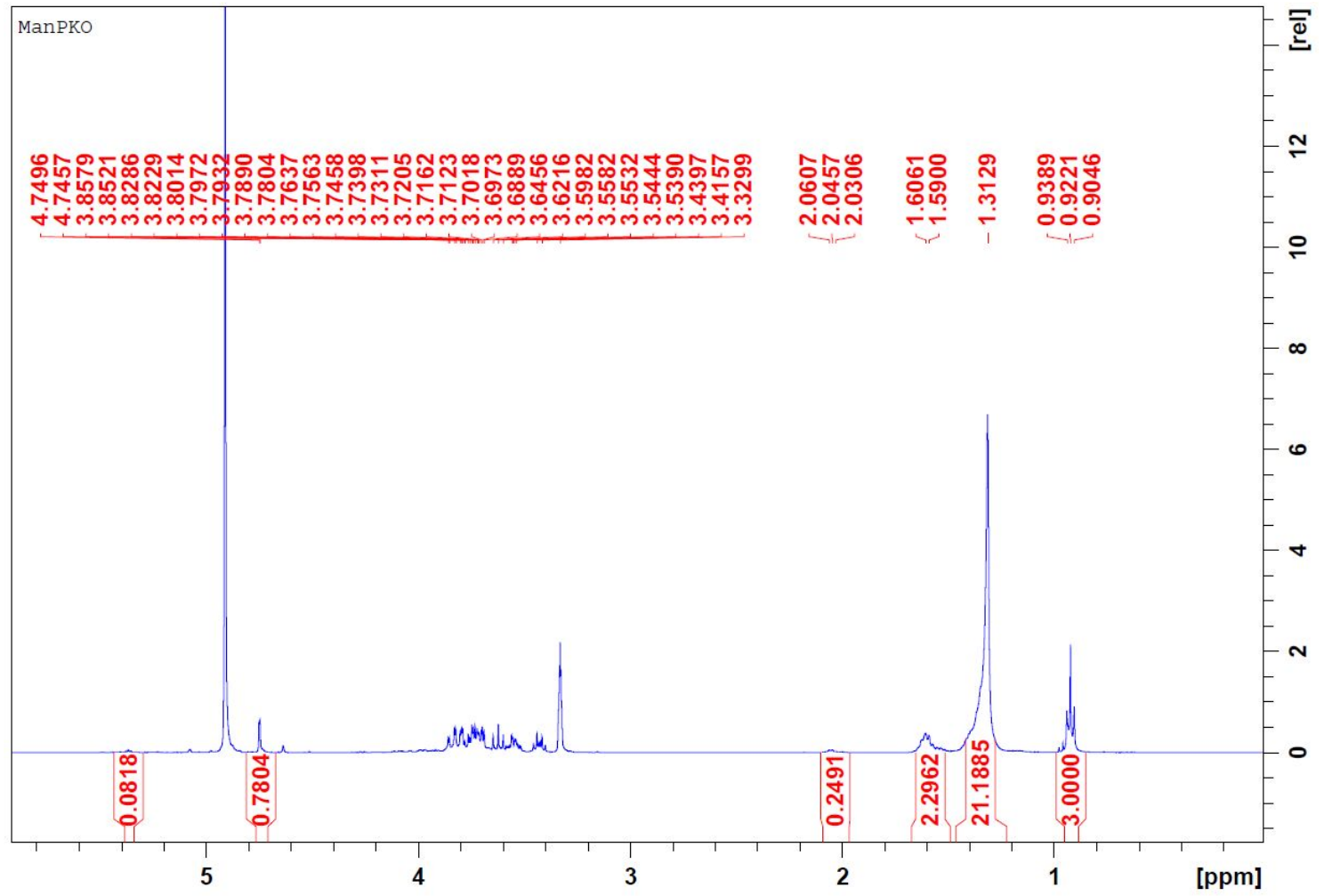

Figure ESI1. ${ }^{1} \mathrm{H}-\mathrm{NMR}$ spectra of $\alpha \mathrm{ManPKO}$ in methanol- $\mathrm{d}_{4}$.

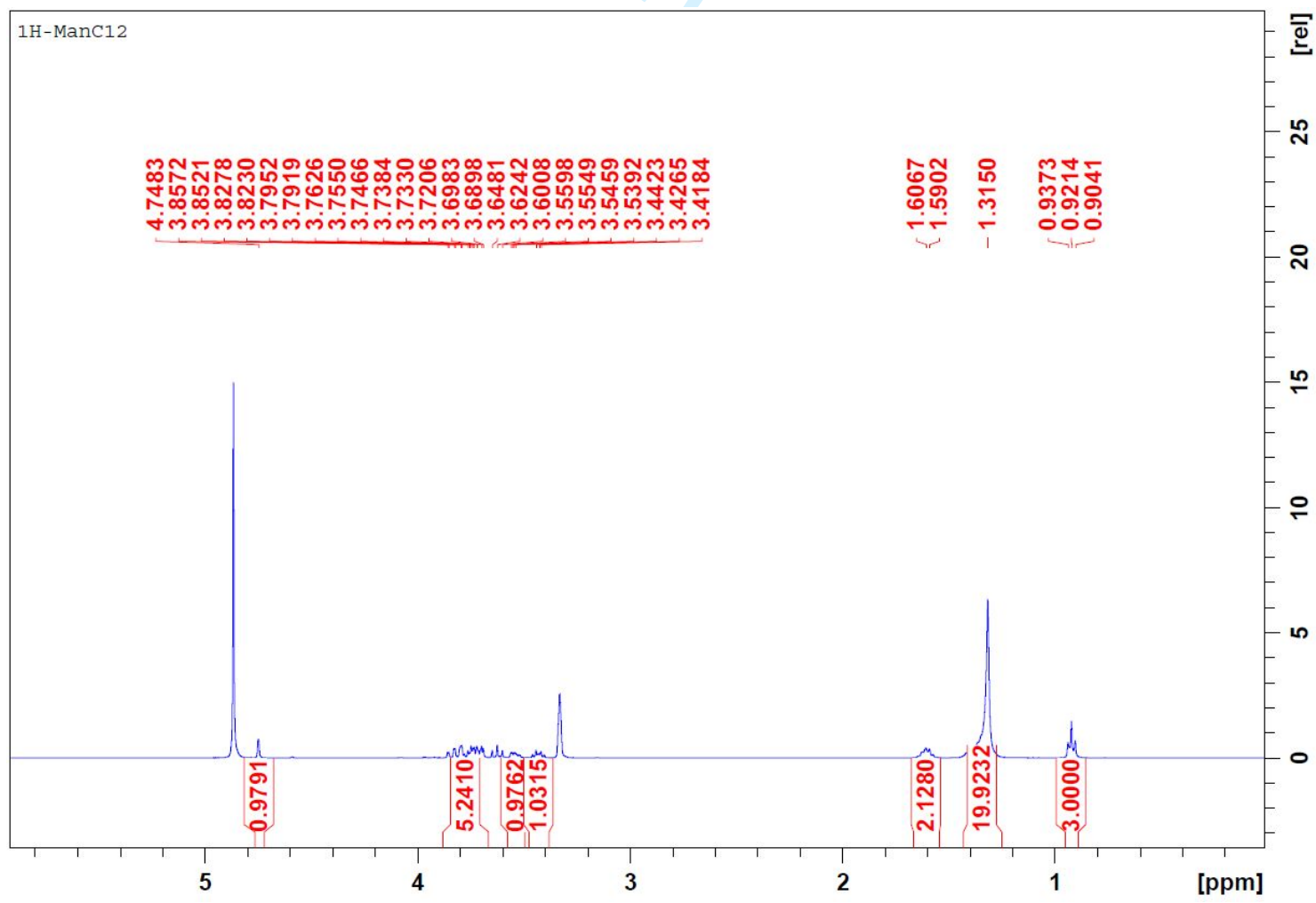

Figure ESI2. ${ }^{1} \mathrm{H}-\mathrm{NMR}$ spectra of $\alpha \mathrm{ManC}_{12}$ in methanol- $\mathrm{d}_{4}$. 


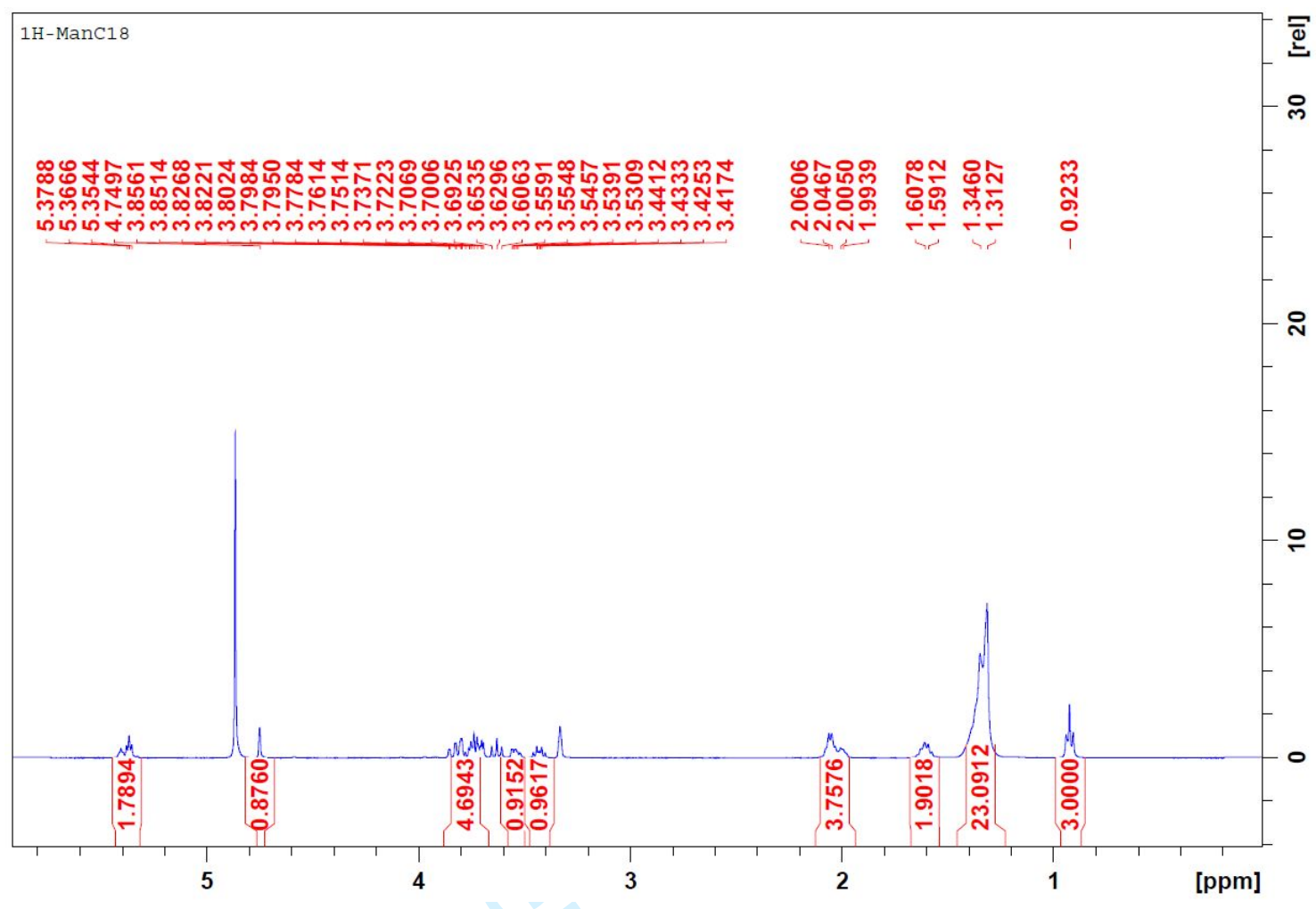

Figure ESI3. ${ }^{1} \mathrm{H}-\mathrm{NMR}$ spectra of $\alpha \mathrm{ManC}_{18: 1}$ in methanol- $\mathrm{d}_{4}$. 


\section{Gas chromatography-mass spectroscopy, GC-MS.}

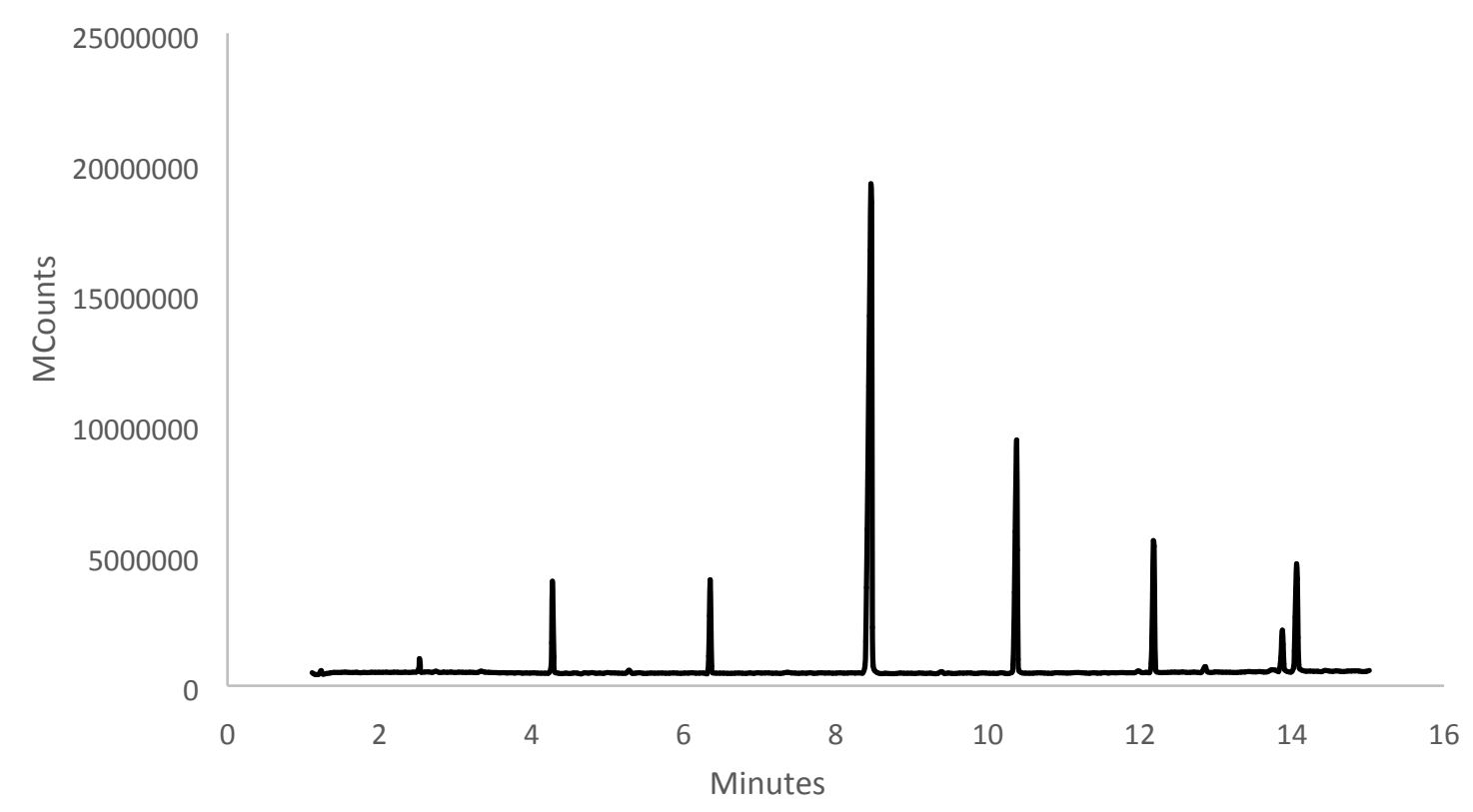

Figure ESI4. GC-MS chromatogram of PKO after reduction showing composition of fatty alcohols.

The PKO sample was measured using a $30 \mathrm{~m}$ x $0.250 \mathrm{~mm}$ ID $\times 0.25 \mu \mathrm{m}$ column, programmed from $75^{\circ} \mathrm{C}$ to $300^{\circ} \mathrm{C}$ at $10^{\circ} \mathrm{C} / \mathrm{min}$, and then the final temperature was held for five minutes. The temperatures of the injector and detector were set at $280^{\circ} \mathrm{C}$ and $360^{\circ} \mathrm{C}$, respectively. Helium was used as carrier gas.

Table ESI1 Palm kernel oil fatty alcohol composition

\begin{tabular}{llc}
\hline Peak, min & Fatty alcohol & Composition, $\%$ \\
\hline $\mathbf{4 . 2 8}$ & C 8 & 4.6 \\
\hline $\mathbf{6 . 3 5}$ & C10 & 4.5 \\
\hline $\mathbf{8 . 4 7}$ & C12 & 49.6 \\
\hline $\mathbf{1 0 . 3 8}$ & C14 & 16.1 \\
\hline $\mathbf{1 2 . 1 8}$ & C16 & 8.4 \\
\hline $\mathbf{1 3 . 8 7}$ & C18 & 2.5 \\
\hline $\mathbf{1 4 . 0 6}$ & C18:1 & 7.6 \\
\hline
\end{tabular}




\section{Polarised Optical Microscopy images, POM.}

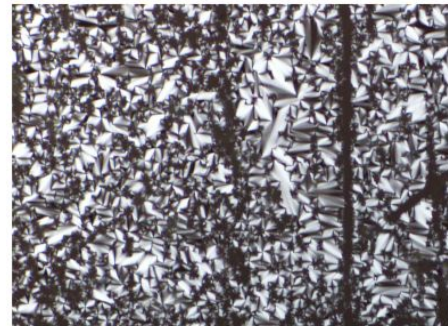

(a)

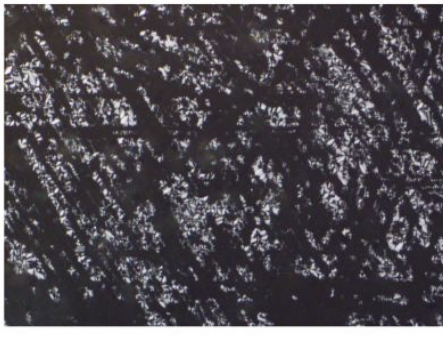

(b)

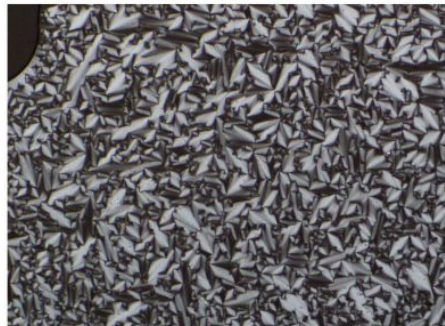

(c)

Figure ESI4. POM images obtained for (a) $\alpha \mathrm{ManC}_{12}, \mathrm{~T}=110^{\circ} \mathrm{C}$, (b) $\alpha \mathrm{ManPKO}, \mathrm{T}=80$ ${ }^{\circ} \mathrm{C}$ and (c) $\alpha \operatorname{ManC}_{18: 1}, \mathrm{~T}=124^{\circ} \mathrm{C}$. 


\section{POM images for the samples in ITO cell}

(a) Planar alignment

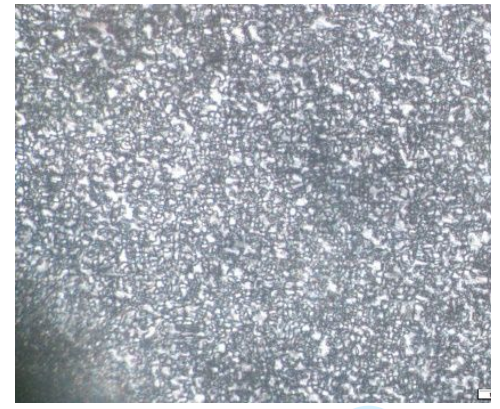

$29^{\circ} \mathrm{C}$

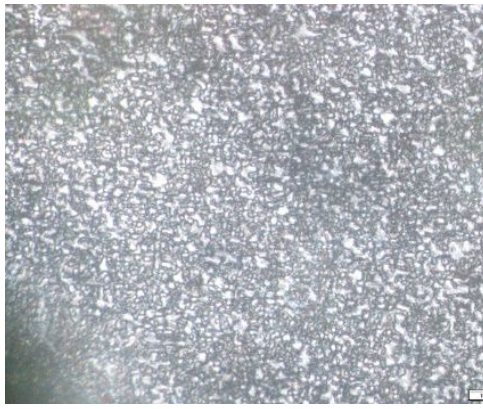

$125^{\circ} \mathrm{C}$

(b) Homeotropic alignment

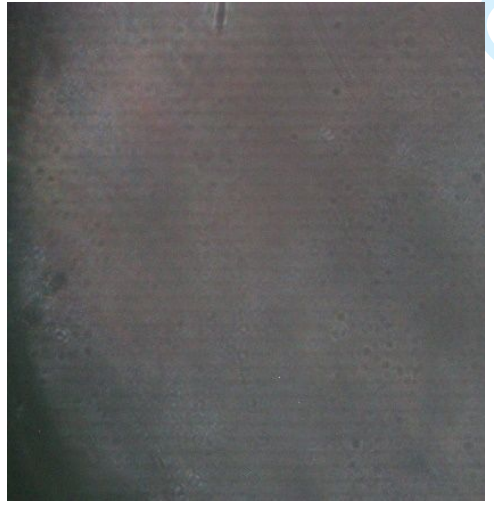

$29^{\circ} \mathrm{C}$

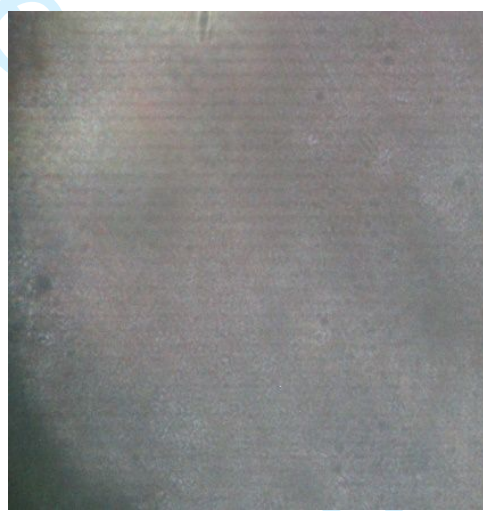

$125^{\circ} \mathrm{C}$

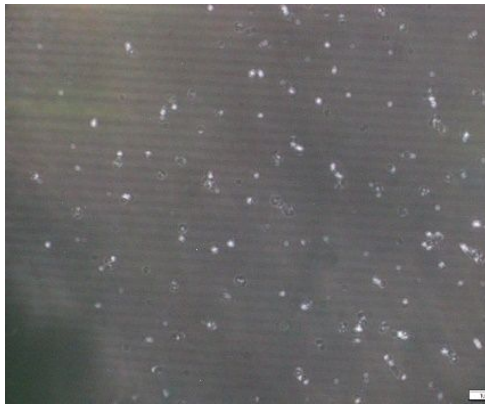

$148^{\circ} \mathrm{C}$

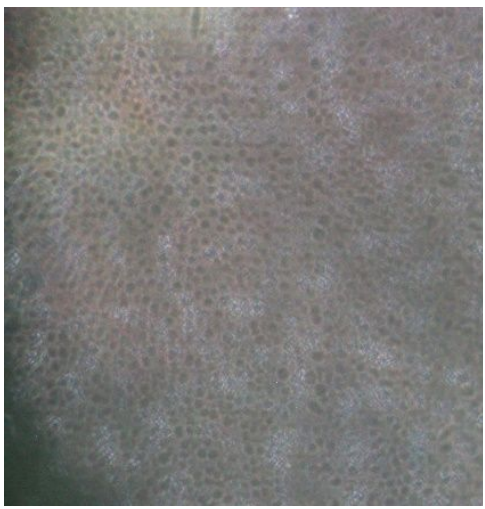

$148^{\circ} \mathrm{C}$

\section{Heating}

Figure ESI5. POM images obtained for ManPKO samples in the ITO cell with surfacetreated substrates for planar and homeotropic alignment on heating. 


\section{Static permittivity for planar and homeotropic alignments}

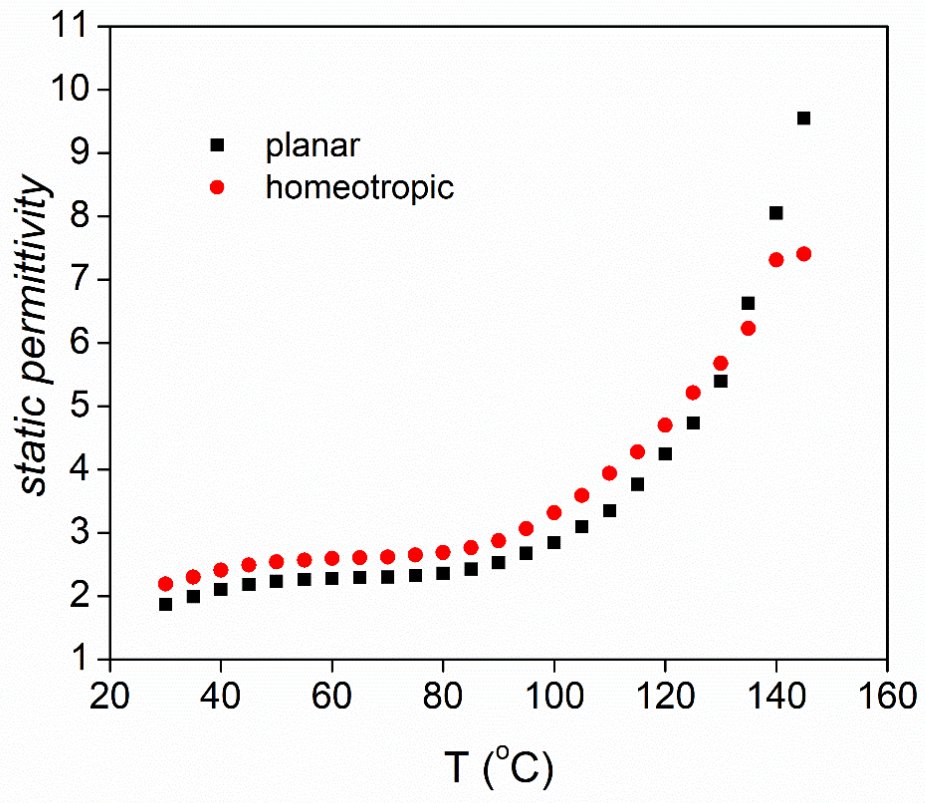

Figure ESI6. Static permittivity versus temperature for planar and homeotropic alignments of ManPKO. 
